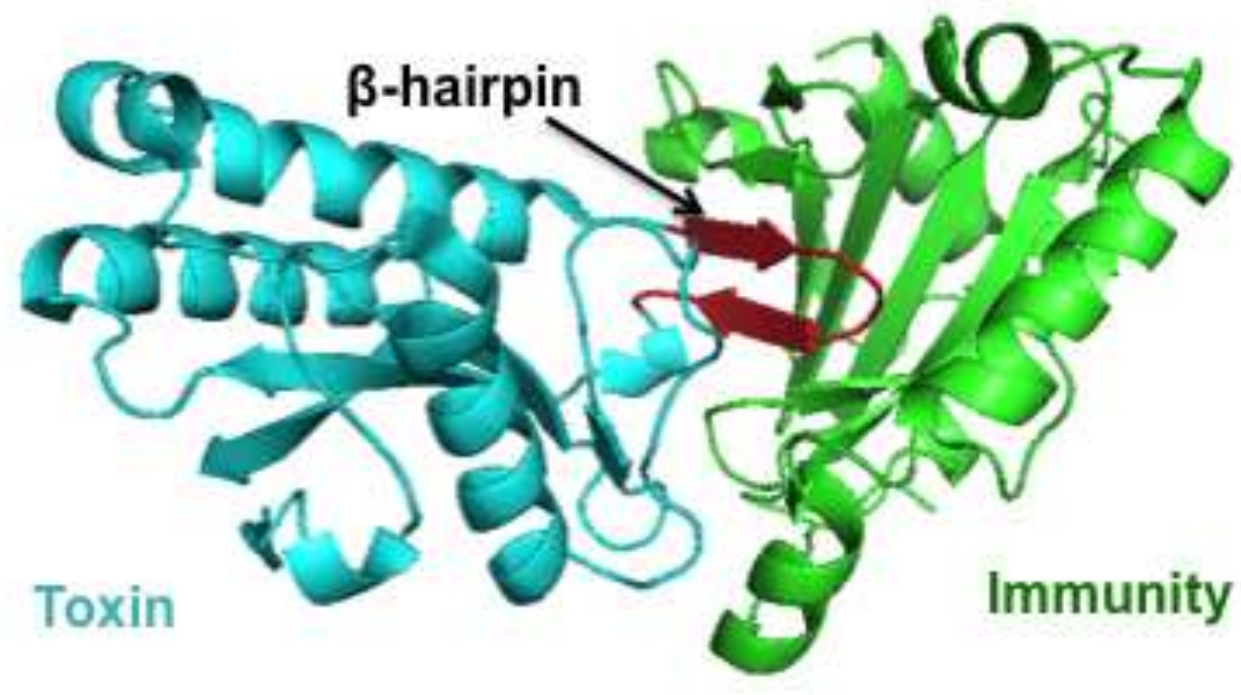

Toxin

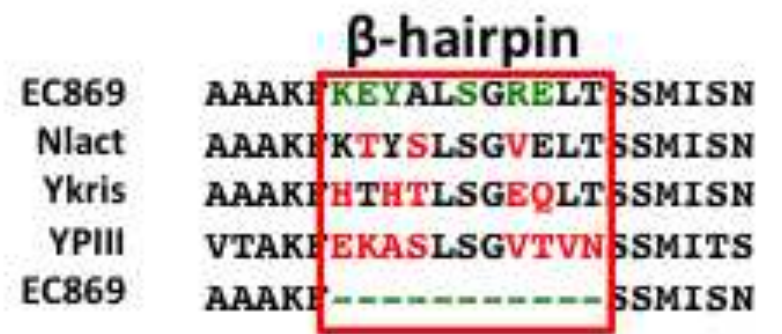

$k d$ for

Immunity

$18 \mathrm{nM}$

$175 \mathrm{nM}$

$4600 \mathrm{nM}$

$1300 \mathrm{nM}$

No binding 


\section{Diversification of $\beta$-augmentation interactions between CDI toxin/immunity proteins}

Robert P. Morse ${ }^{1}$, Julia L. E. Willett ${ }^{2}$, Parker M. Johnson ${ }^{1}$, Mandy Zheng ${ }^{3}$, Alfredo Credali ${ }^{1}$, Angelina Iniguez ${ }^{1}$, James S. Nowick ${ }^{3}$, Christopher S. Hayes ${ }^{2,4}$ and Celia W. Goulding ${ }^{1,5}$

${ }^{1}$ Department of Molecular Biology and Biochemistry

${ }^{3}$ Department of Chemistry

${ }^{5}$ Department of Pharmaceutical Sciences

University of California, Irvine

Irvine, CA 92697

${ }^{2}$ Department of Molecular, Cellular and Developmental Biology

${ }^{4}$ Biomolecular Science and Engineering Program

University of California, Santa Barbara

Santa Barbara, CA 93106-9625

*Corresponding author: Celia Goulding, E-mail: celia.goulding@uci.edu, Phone: (949) 824-0337, Fax: (949) 824-8551

Keywords: bacterial competition; interspecies growth inhibition; DNase; toxin/immunity proteins 


\section{Abstract}

Contact-dependent growth inhibition (CDI) is a wide-spread mechanism of inter-bacterial competition mediated by the CdiB/CdiA family of two-partner secretion proteins. CdiA effectors carry diverse $\mathrm{C}$-terminal toxin domains (CdiA-CT), which are delivered into neighboring target cells to inhibit growth. $\mathrm{CDI}^{+}$bacteria also produce Cdil immunity proteins that bind specifically to cognate CdiA-CT toxins and protect the cell from auto-inhibition. Here, we compare the structures of homologous CdiACT/Cdil complexes from Escherichia coli EC869 and Yersinia pseudotuberculosis YPIII to explore the evolution of CDI toxin/immunity protein interactions. Both complexes share an unusual $\beta$-augmentation interaction, in which the toxin domain extends a $\beta$-hairpin into the immunity protein to complete a sixstranded anti-parallel sheet. However, the specific contacts differ substantially between the two complexes. The EC869 $\beta$-hairpin interacts mainly through direct $\mathrm{H}$-bond and ion-pair interactions, whereas the YPIII $\beta$-hairpin pocket contains more hydrophobic contacts and a network of bridging water molecules. In accord with these differences, we find that each Cdil protein only protects target bacteria from its cognate $\mathrm{CdiA}-\mathrm{CT}$ toxin. The compact $\beta$-hairpin-binding pocket within the immunity protein represents a tractable system for the rationale design of small molecules to block CdiA-CT/Cdil complex formation. We synthesized a macrocyclic peptide mimic of the $\beta$-hairpin from EC869 toxin and solved its structure in complex with cognate immunity protein. These latter studies suggest that small molecules could potentially be used to disrupt CDI toxin/immunity complexes. 


\section{Abbreviations}

Contact-dependent growth inhibition, CDI; C-terminal toxin of CdiA, CdiA-CT; immunity protein, Cdil;

Escherichia coli EC869, EC869; Yersinia pseudotuberculosis YPIII, YP III; Enterobacter cloacae ATCC 13047, ECL; Burkholderia pseudomallei 1026b, Bp1026b; Yersinia kristensenii ATCC 33638, Ykris; Neisseria lactamica ATCC 23970, Nlact; circular dichroism, CD; macrocyclic, MAC. 


\section{Introduction}

Bacteria possess many strategies to compete and cooperate with other microorganisms in the environment. Contact-dependent growth inhibition (CDI) is one competitive mechanism used by some Gram-negative species to inhibit the growth of neighboring bacteria ${ }^{1 ; 2} \cdot \mathrm{CDI}^{+}$cells express $\mathrm{CdiB} / \mathrm{CdiA}$ two-partner secretion systems, which deliver protein toxins into target bacteria through a receptormediated process. CdiB is an Omp85 outer-membrane protein that exports and assembles toxic CdiA effectors onto the surface of $\mathrm{CDI}^{+}$cells. CdiA proteins range from $180-630 \mathrm{kDa}$ depending on bacterial species and form $\beta$-helical filaments that are predicted to extend several hundred $\AA$ from the inhibitor-cell surface. CdiA binds to specific receptors on susceptible bacteria and subsequently delivers a toxin domain derived from its C-terminus (CdiA-CT) into the target cell ${ }^{3 ; 4 ; 5}$. $\mathrm{CDI}^{+}$bacteria deploy a variety of CdiA-CT toxins with distinct activities. The CdiA-CT ${ }^{\mathrm{EC} 93}$ from Escherichia coli EC93 dissipates ion gradients by forming membrane pores ${ }^{6}$, but most other characterized CDI toxins have specific nuclease activities. CDI toxins from E. coli EC869 and Dickeya dadantii 3937 are potent DNases capable of degrading target-cell chromosomes ${ }^{5 ; 7}$, and $\mathrm{CdiA}-\mathrm{CT}^{\mathrm{ECL}}$ from Enterobacter cloacae ATCC 13047 cleaves $16 \mathrm{~S}$ rRNA to block protein synthesis ${ }^{8}$. $\mathrm{CDI}^{+}$bacteria protect themselves from autoinhibition by producing small Cdil immunity proteins that bind to the CdiA-CT and block its toxin activity. Because CDI toxins are diverse, CdiA-CT/Cdil protein interactions are necessarily specific between cognate pairs. Therefore, Cdil immunity proteins neutralize their cognate CdiA-CT, but provide no protection against the toxins deployed by other bacteria ${ }^{7 ; 9}$. This diverse network of toxin/immunity pairs suggests that CDI plays an important role in inter-cellular competition and self/non-self recognition.

We recently surveyed the Uniprot database and identified at least 120 distinct CdiA-CT toxin families. Only 26 of these toxins have Pfam designations ${ }^{10}$ and the remaining domains are uncharacterized. We initiated structural studies of these protein pairs to discover new toxin activities and toxin/immunity binding interactions. The first CDI toxin/immunity protein complex structures to be determined were from Burkholderia pseudomallei 1026b and enterohemorrhagic E. coli strain EC869 ${ }^{7}$. The CdiA-CT toxin sequences from these bacteria are not related, yet the three-dimensional structures 
of the domains superimpose with an rmsd of $3.9 \AA$. Structural homology searches revealed significant similarity to type IIS restriction endonucleases, suggesting that both toxins are DNases. Indeed, the Cterminal domain of CdiA-CT ${ }_{011}{ }^{\mathrm{EC} 869}$ has potent $\mathrm{Zn}^{2+}$-dependent DNase activity in vitro and in vivo ${ }^{7}$. However, CdiA-CT ${ }_{\| 1}^{\mathrm{Bp1026b}}$ has no detectable activity on DNA, and instead this toxin preferentially cleaves near the $3^{\prime}$-end of tRNA ${ }^{\text {Ala }}$ molecules ${ }^{11}$. Thus, the same toxin fold is used to target different nucleic acid substrates. Though $\mathrm{CdiA}-\mathrm{CT}_{011}{ }^{\mathrm{EC} 869}$ and $\mathrm{CdiA}-\mathrm{CT}_{\|}{ }^{\mathrm{Bp1026b}}$ are similar in structure, other CDI toxins do not share the type IIS restriction endonuclease fold. The crystal structure of CdiA-CT ${ }^{\mathrm{ECL}}$ from E. cloacae ATCC 13047 reveals similarity to the C-terminal nuclease domain of colicin E3 ${ }^{8 ; 12 ; 13}$, and sequence homology and activity studies strongly suggest that $\mathrm{CdiA}-\mathrm{CT}^{\mathrm{K} 96243}$ from $B$. pseudomallei K96243 is related to the C-terminal nuclease domain of colicin E5 ${ }^{2 ; 11}$. Moreover, Aravind and colleagues have predicted that CDI systems deploy two classes of RNA deaminase (Pfam: PF14424 and PF14437), as well as homologues of the EndoU poly(U)-specific endonuclease that processes eukaryotic snoRNAs (Pfam: PF14436) ${ }^{10 ; 14 ; 15}$. Thus, CDI represents a versatile platform to deliver structurally diverse toxins into Gram-negative bacteria.

Although toxin/immunity pairs within a given family are homologous, there is often considerable sequence diversity between members, suggesting that families continue to diverge and evolve. When viewed in the context of available crystal structures, it is apparent that residues at the interface of the toxin/immunity protein complexes are diversifying most rapidly. This phenomenon is exemplified by toxin/immunity proteins that are homologous to the orphan-11 (011) CdiA-CT/Cdil pair from E. coli EC869 ${ }^{7 ; 9} \cdot$ CdiA-CT $_{011}{ }^{E C 869}$ interacts with $\mathrm{Cdil}_{011}{ }^{\mathrm{EC} 869}$ through $\beta$-augmentation, in which the toxin domain extends a $\beta$-hairpin to complete a six-stranded anti-parallel $\beta$-sheet within the immunity protein (Fig. 1A) ${ }^{7}$. The sequences encoding the $\beta$-hairpin (corresponding to $\beta 4$ and $\beta 5$ ) are the most variable between members of the CdiA-CT ${ }_{011}{ }^{\mathrm{EC} 869}$ nuclease family (Fig. 1B). Moreover, Cdil $_{011}{ }^{\mathrm{EC} 869}$ residues that interact with the toxin are not conserved between related immunity proteins (Fig. 1C), suggesting that each immunity protein is specific for its cognate toxin. Here, we use structure-function analyses to examine the $\beta$-augmentation interactions of two homologous CdiA-CT/Cdil complexes to study the diversification of CDI toxin/immunity protein interfaces. We find that the CdiA-CT/Cdil ${ }^{\text {YPIII }}$ complex from 
Yersinia pseudotuberculosis YPIII also features a $\beta$-augmentation interaction, however the precise intermolecular contacts differ substantially between the complexes. In accord with these differences, each Cdil immunity protein only protects against its cognate toxin, demonstrating that each pair is a distinct cognate toxin/immunity pair. Finally, we synthesized a macrocyclic peptide mimic of the $\beta$ hairpin from CdiA-CT ${ }_{011}{ }^{\mathrm{EC} 869}$ and solved its crystal structure in complex with the $\mathrm{Cdil}_{011}{ }^{\mathrm{EC} 869}$ immunity protein. This structure forms the basis to refine the $\beta$-hairpin mimic to increase affinity with the goal of producing compounds that activate DNase toxins through sequestration of immunity proteins.

\section{Results}

\section{Structure of the CdiA-CT/C dil ${ }^{\text {YPIII }}$ complex reveals conservation of the $\beta$-augmentation interaction}

Alignment of CdiA-CT ${ }_{011}{ }^{E C 869}$ toxin homologues indicates that most secondary-structure elements have high sequence conservation with the exception of strands $\beta 4$ and $\beta 5$, which mediate the $\beta$-augmentation interaction with $\mathrm{Cdil}_{011}{ }^{\mathrm{EC} 869}$ (Figs. 1A \& 1B). To determine whether $\beta$-augmentation occurs in other homologous toxin/immunity pairs, we performed structural and functional analyses of the CdiA-CT/Cdil ${ }^{\text {YPIII }}$ complex encoded by the YPK_0575/YPK_0576 genes of Yersinia pseudotuberculosis YPIII. The C-terminal nuclease domain of CdiA-CT ${ }^{\mathrm{YPIII}}$ is $70.4 \%$ identical to CdiA$\mathrm{CT}_{011}{ }^{\mathrm{EC} 869}$ and shares all of the predicted active-site residues (Fig. 1B). Similarly, the Cdil ${ }^{\text {YPIII }}$ and Cdil $_{011}{ }^{\mathrm{EC} 869}$ immunity proteins share $49.1 \%$ identity, though Cdil ${ }^{\text {YPIII }}$ contains a 10-residue insertion between $\alpha 1$ and $\alpha 2$ that is predicted to produce an elongated loop (Fig. 1C). We solved the crystal structure of the CdiA-CT/CdilYPIII complex to $2.1 \AA$ resolution by molecular replacement using the structure of the CdiA-CT/Cdil ${ }_{011}{ }^{\mathrm{EC} 869}$ complex (PDB code: $4 \mathrm{G6U}$ ) as a search model (Fig. 2A). As with other CdiA-CTs ${ }^{7 ; 8}$, the N-terminal region (residues Val1 - Gly173) was not resolved in the structure. The final model included $\mathrm{CdiA}-\mathrm{CT}^{\mathrm{YPIII}}$ residues $174-298$ and 148 water molecules resulting in an $\mathrm{R}_{\text {work }} / \mathrm{R}_{\text {free }}(\%)$ of 20.5/25.6 (Table 1). The CdiA-CT/Cdil ${ }_{011}{ }^{\mathrm{EC} 869}$ and CdiA-CT/Cdil ${ }^{\text {YIII }}$ complexes have very similar structures. The toxin domains superimpose with rmsd of $0.84 \AA$ over 101 of $123 \alpha$-carbons, and the immunity proteins with rmsd of $1.01 \AA$ over 133 of 173 a-carbons (Fig. 2B). The CdiA- 
$\mathrm{CT} / \mathrm{Cdil}^{\text {YPIII }}$ complex also contains a $\beta$-augmentation interaction in which the toxin extends its $\beta 4 / \beta 5$ hairpin into binding pocket within the immunity protein (Figs. 2A \& 2B). However, in contrast to CdiA$\mathrm{CT}_{011}{ }^{\mathrm{EC} 869}$, which contains an ordered $\mathrm{Zn}^{2+}$ ion in the active site ${ }^{7}$, no zinc was detected by metal $\mathrm{K}$ edge absorption analysis of multiple CdiA-CT/Cdil ${ }^{\text {YPIII }}$ crystals and the electron density spheres within the active site vicinity of $\mathrm{CdiA}-\mathrm{CT}^{\mathrm{YPIII}}$ where not within zinc coordinating distances with the catalytic residues or would form a zinc tetra- or hexa-coordination sphere, and thus were modeled as water molecules (Fig. S2).

CdiA-CT ${ }^{\text {YPIII }}$ and $\mathrm{Cdil}^{\mathrm{YPIII}}$ bind one another through a network of 14 direct $\mathrm{H}$-bonds and ion-pairs (Table S1) combined with several hydrophobic interactions. Only two CdiA-CT ${ }^{\mathrm{YPIII}} \beta$-hairpin side-chains (Glu242 and Lys243) interact directly with CdilYPIII, compared to the six direct side-chain interactions in the CdiA-CT/Cdil ${ }_{011}{ }^{\mathrm{EC} 869}$ complex (Table S1 \& Fig. 3). The CdiA-CT/CdilY ${ }^{\mathrm{YPII}} \beta$-hairpin pocket also contains a network of bridging water molecules and several more hydrophobic interactions than the CdiA-CT/Cdil ${ }_{011}{ }^{\mathrm{EC} 869}$ complex (Fig. 3). In addition, extensive interactions outside of the $\beta$-augmentation region contribute to CdiA-CT/C dil ${ }^{\text {YPIII }}$ complex stability. Loop L1 of CdiA-CT ${ }^{\text {YPIII }}$ forms several

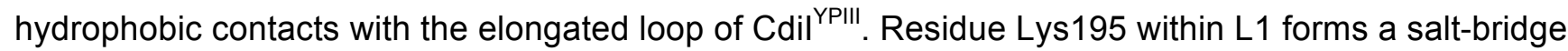
with Cdil $^{\text {YPIII }}$ residue Glu137 within $\beta 6$. The loop connecting strands $\beta 2$ and $\beta 3$ also has several $H$-bond interactions and Asp201 forms a prominent salt-bridge with Arg69 in the elongated loop of Cdil ${ }^{\text {YPIII }}$ (Table S1 \& Fig. 2B). In contrast, the CdiA-CT/Cdil ${ }_{011}{ }^{\mathrm{EC} 869}$ complex has a less extensive interaction network outside of the $\beta$-augmentation region. Loop L1 of CdiA-CT ${ }_{011}{ }^{\mathrm{EC} 869}$ has fewer hydrophobic contacts and one ionic interaction between Asp183 and Arg71 of Cdil ${ }_{011}{ }^{\mathrm{EC} 869}$ (Table S1). Together, these structures reveal overall conservation between the toxin/immunity protein pairs, but reveal important differences in the network of bonds that stabilize each complex (Fig. S3).

\section{$\mathrm{Cdil}_{011}{ }^{\mathrm{EC} 869}$ and $\mathrm{Cdil}{ }^{\mathrm{YPIII}}$ immunity proteins are specific for their cognate toxins}

The conservation of nuclease active-site residues strongly suggests that $\mathrm{CdiA}-\mathrm{CT}^{\mathrm{YPIII}}$ has DNase activity similar to that described for CdiA-CT ${ }_{011}{ }^{E C 869} 7$. We isolated the CdiA-CT ${ }^{\text {YPIII }}$ domain from its immunity protein and tested for DNase activity in vitro using supercoiled plasmid as a substrate. 
CdiA-CT ${ }^{\text {YPIII }}$ had no detectable nuclease activity in the presence of $\mathrm{Mg}^{2+}$ ions, but converted the supercoiled plasmid into open-circular form when the reactions were supplemented with $\mathrm{Zn}^{2+}$ (Fig. 4). CdiA-CT ${ }^{\text {YPIII }}$ appears to be less active than the $\mathrm{CdiA}_{-} \mathrm{CT}_{011}{ }^{\mathrm{EC} 869}$ toxin, which had detectable DNase activity with $\mathrm{Mg}^{2+}$ and completely degraded the plasmid in the presence of $\mathrm{Zn}^{2+}$ ions (Fig. 4). We next tested the Cdil ${ }^{\mathrm{YPIII}}$ and $\mathrm{Cdil}_{011}{ }^{\mathrm{EC} 869}$ immunity proteins for the ability to neutralize DNase activity in vitro. Each immunity protein was able to partially block the activity of its cognate toxin, but had no effect on non-cognate toxin activity (Fig. 4). These results strongly suggest that each immunity protein only binds to its cognate toxin. We measured the dissociation constants $\left(K_{d}\right)$ for cognate and non-cognate complexes using biolayer interferometry. CdiA-CT ${ }^{\mathrm{YPIII}}$ and $\mathrm{Cdil}{ }^{\mathrm{YPIII}}$ form a high-affinity complex with $\mathrm{K}_{d}=$ $16 \pm 1 \mathrm{nM}$, which is similar to the value $(18 \pm 7 \mathrm{nM})$ previously reported for the CdiA-CT/Cdil ${ }_{011}$ EC869 complex $^{7}$. In contrast, Cdil ${ }^{\text {YPIII }}$ has $\sim 1,000$-fold lower affinity for non-cognate CdiA-CT ${ }_{011}{ }^{\text {EC869 }}$ with a $\mathrm{K}_{d}$ of $13 \pm 2 \mu \mathrm{M}$. This highly reduced affinity between $\mathrm{CdiA}-\mathrm{CT}_{011}{ }^{\mathrm{EC} 869}$ and Cdil ${ }^{\mathrm{YPIII}}$ compared to cognate protein pairs is perhaps due, in part, to the shape and electrostatic incompatibility of the CdiA-CT $\mathrm{T}_{011} \mathrm{EC} 869$

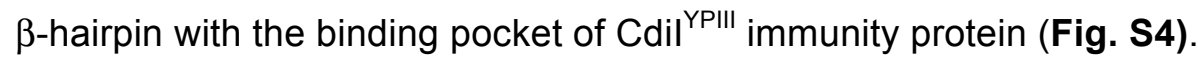

\section{Immunity proteins only provide protection against their cognate toxins during CDI}

The CdiA-CT ${ }^{\text {YIII }}$ toxin is encoded within a defective cdi locus that has been inactivated by complex gene rearrangements and deletions. To ascertain whether the toxin is functional in cellmediated CDI, we fused the $\mathrm{CdiA}-\mathrm{CT}^{\mathrm{YPIII}}$ nuclease domain to the $\mathrm{C}$-terminus of $\mathrm{CdiA}{ }^{\mathrm{EC} 93}$ and tested the resulting chimera for inhibition activity against $E$. coli target cells. Inhibitor cells that express the $\mathrm{CdiA}^{\mathrm{EC93}}-\mathrm{CT}^{\mathrm{YPIII}}$ chimera reduced viable target-cell counts more than 500 -fold after four hours of coculture, but target cells that express the cognate $\mathrm{Cdil}^{\mathrm{YPIII}}$ immunity protein were completely protected from inhibition (Fig. 5A). In contrast, target cells that express Cdil ${ }_{011}{ }^{\mathrm{EC} 869}$ immunity protein were inhibited to the same extent as cells that lack any immunity gene (Fig. 5A). Similarly, the Cdil ${ }^{\text {YPIII }}$ immunity protein was unable to protect target cells from inhibitor cells that deploy the CdiA-CT ${ }_{011}{ }^{E C 869}$ toxin (Fig. 5A). We also examined competition co-cultures by fluorescence microscopy to detect DNase activity in target bacteria. We labeled inhibitor cells with YFP and target cells with mKate2 to 
differentiate the two populations and also stained the cells with DAPI to visualize nucleoids.

Immediately after cell mixing, both inhibitor and target cell populations had similar morphologies and nucleoid staining was uniform (Fig. 5B). After four hours of co-culture, target cells that lack the appropriate immunity protein became filamentous and lost DAPI staining (Fig. 5B \& Fig. S5), indicating significant damage to the chromosome. In contrast, target cells that express cognate Cdil immunity proteins retained normal morphology and DAPI staining (Fig. 5B \& Fig. S5). Together, these data demonstrate that these two toxin/immunity systems have diverged into distinct non-overlapping immunity groups.

\section{$\beta$-augmentation is required for toxin/immunity protein complex formation}

The $\beta$-augmentation interactions observed in the two toxin/immunity protein complexes suggest that the proteins bind using a lock-and-key mechanism. Therefore, we sought to crystallize and solve the structures of isolated toxins and immunity proteins to determine if the proteins undergo any conformational changes upon complex formation. Neither of the isolated toxin domains formed crystals, but we were able to crystallize and solve the $1.8 \AA$ structure of an isolated immunity protein (Cdil ${ }^{\text {Ykris }}$ ) encoded by the Ykris_10740 locus of Yersinia kristensenii ATCC 33638 (Table 1). Cdil ${ }^{\text {Ykris }}$ shares 68.9\% and $51.5 \%$ sequence identity with $\mathrm{Cdil}_{011}{ }^{\mathrm{EC} 869}$ and Cdil ${ }^{\mathrm{YPIII}}$ (respectively) (Fig. 1C), and its structure superimposes onto $\mathrm{Cdil}_{011}{ }^{\mathrm{EC} 869}$ and $\mathrm{Cdil}^{\mathrm{YPIII}}$ with rmsd of 0.626 and $0.984 \AA$ over all $\alpha$-carbons (respectively) (Fig. S6). In addition, structural homology searches identified yet another immunity protein homolog (Cdil ${ }^{\mathrm{NMB}}$ ) encoded by the NMB0488 locus in Neisseria meningitidis MC58 (PDB: $2 \mathrm{GKP}) . \mathrm{Cdil}^{\mathrm{NMB}}$ superimposes onto each of the other immunity proteins with rmsd values $<0.7 \AA$ over all a-carbons (Fig. S6). Collectively, these structures indicate that $\mathrm{Cdil}_{011}{ }^{\mathrm{EC} 869}$ homologues retain the same $\beta$-hairpin binding pocket architecture in the absence of bound toxin. This finding suggests that $\beta$ hairpins are modular, raising the possibility that interaction specificity could be altered by exchanging $\beta 4 / \beta 5$ ( $\beta$-hairpin) sequences between toxins.

To test whether $\beta$-augmentation is required for stable complex formation, we replaced the CdiA$\mathrm{CT}_{011}{ }^{\mathrm{EC} 869} \beta$-hairpin (residues Lys242 - Thr252) with a Gly-Ser-Gly peptide linker to generate CdiA- 
$\mathrm{CT}_{011}{ }^{\mathrm{EC} 869 / \triangle \beta 4 \beta 5}$ (Fig. 6A). Wild-type CdiA-CT ${ }_{011}{ }^{\mathrm{EC} 869}$ binds to its cognate immunity protein with nanomolar affinity and co-purifies with $\mathrm{His}_{6}$-tagged $\mathrm{Cdil}_{011}{ }^{\mathrm{EC} 869}$ during $\mathrm{Ni}^{2+}$-affinity chromatography (Fig. 6B). In contrast, CdiA-CT ${ }_{011}{ }^{E C 869 / \triangle \beta 4 \beta 5}$ did not co-purify with $\mathrm{His}_{6}$-tagged $\mathrm{Cdil}_{011}{ }^{\mathrm{EC} 869}$ (Fig. 6B), suggesting the mutant domain has lower affinity for immunity protein. We purified CdiA-CT ${ }_{011} \mathrm{EC} 69 \mathrm{~A} / \Delta \beta 4 \beta 5$ to homogeneity by anion-exchange chromatography and measured its affinity for $\mathrm{Cdil}_{\mathrm{o} 11}{ }^{\mathrm{EC} 869}{ }_{-\mathrm{His}}{ }_{6} \mathrm{using}$ biolayer interferometry. However, no binding interaction was detected, indicating that the dissociation constant is $>300 \mu \mathrm{M}$. To test whether deletion of the $\beta$-hairpin disrupts toxin structure, we examined the $\mathrm{CdiA}_{-} \mathrm{CT}_{011}{ }^{\mathrm{EC} 869 / \triangle \beta 4 \beta 5}$ domain using circular dichroism (CD) spectroscopy. This analysis revealed that CdiA-CT ${ }_{011}{ }^{E C 869 / \triangle \beta 4 \beta 5}$ has essentially the same secondary structure content as the wild-type domain (Fig. 6C). Taken together, these results demonstrate that the CdiA-CT ${ }_{011}{ }^{\mathrm{EC} 869} \beta$-hairpin is critical for

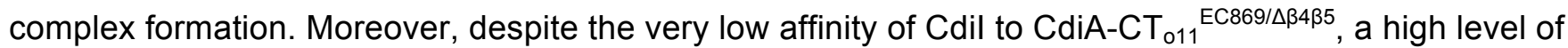
expression of CdiA-CT ${ }_{011}{ }^{E C 869 / \triangle \beta 4 \beta 5}$ was observed (Fig. 6B) together with healthy cell growth, suggesting that the $\beta$-hairpin is also required for toxic DNase activity. This was confirmed by testing in vitro DNase activity in the presence of supercoiled plasmid DNA and $\mathrm{Zn}^{2+}$, which showed that the CdiA$\mathrm{CT}_{011}{ }^{\mathrm{EC} 869 / \triangle \beta 4 \beta 5}$ domain had no observable DNase activity (data not shown).

We next asked whether Cdil binding specificity can be altered by grafting heterologous $\beta$ hairpins onto the $\mathrm{CdiA}-\mathrm{CT}_{\mathrm{011}}{ }^{\mathrm{EC} 869}$ toxin. Using a catalytically inactive version of $\mathrm{CdiA}-\mathrm{CT}_{011}{ }^{\mathrm{EC} 869}$ that contains the Asp198Ala mutation, we replaced residues Lys242 - Glu250 with the corresponding sequences from homologous toxins from Y. kristensenii ATCC 33638 (CdiA-CT ${ }^{\text {Ykris }}$ encoded by ykris0001_10730) and Neisseria lactamica ATCC 23970 (CdiA-CT ${ }^{\text {Nlact }}$ encoded by NEILACOT_05635) (Fig. 7A). We co-expressed CdiA-CT ${ }_{011}{ }^{\mathrm{EC} 869 / \text { Nlact }}$ and $\mathrm{CdiA}-\mathrm{CT}_{011}{ }^{\mathrm{EC} 869 / \mathrm{Ykris}}$ together with His ${ }_{6}$-tagged $\mathrm{Cdil}_{011}{ }^{\mathrm{EC} 869}$ and purified the tagged immunity protein by $\mathrm{Ni}^{2+}$-affinity chromatography. Chimeric CdiA$\mathrm{CT}_{011}{ }^{\mathrm{EC} 869 / \mathrm{Nlact}}$ toxin co-purified with $\mathrm{His}_{6}$-tagged $\mathrm{Cdil}_{011}{ }^{\mathrm{EC} 869}$, but $\mathrm{CdiA}-\mathrm{CT}_{011}{ }^{\mathrm{EC} 869 / \mathrm{rkris}}$ eluted in the void volume of the column (Fig. 7B). These results suggest that $\mathrm{CdiA}-\mathrm{CT}_{011}{ }^{E C 869 / N l a c t}$ binds with relatively high affinity to $\mathrm{Cdil}_{\mathrm{0} 11}{ }^{\mathrm{EC} 869}$, whereas the CdiA-CT ${ }_{011}{ }^{\mathrm{EC} 869 / Y k r i s}$ toxin does not. We first confirmed that each chimeric toxin was folded properly using CD spectroscopy (Fig. 7C), then measured binding affinities for Cdil $_{011}{ }^{E C 869}$ using biolayer interferometry. CdiA-CT ${ }_{011}{ }^{E C 869 / N l a c t}$ and $C d i A-C T_{011}{ }^{E C 869 / Y k r i s ~}$ bound to 
Cdil $_{011}{ }^{\mathrm{EC} 869}$ with dissociation constants of $180 \pm 100 \mathrm{nM}$ and $46 \pm 36 \mu \mathrm{M}$, respectively (Table 2), consistent with the co-purification data. The difference in affinities of the N. lactamica and Y. kristensenii chimeric toxins for the $\mathrm{Cdil}_{011}{ }^{\mathrm{EC} 869}$ immunity protein is in part due to the differences in electrostatic and shape complementarity (Fig. S7). The N. lactamica and EC869 $\beta$-hairpins share similar electrostatics and shape (Figs. S7A \& S7B), allowing CdiA-CT ${ }_{011}{ }^{\text {EC869/Nlact }}$ to retain nanomolar affinity for $\mathrm{Cdil}_{011}{ }^{\mathrm{EC} 869}$ (Table 2). In contrast, the $Y$. kristensenii $\beta$-hairpin has a different shape and altered electrostatics compared with $\mathrm{CdiA}-\mathrm{CT}_{011}{ }^{\mathrm{EC} 869}$, which results in low micromolar affinity of chimeric CdiA-CT ${ }_{011}{ }^{E C 869 / Y k r i s}$ toxin for Cdil $_{011}{ }^{E C 869}$ (Figs. S7A \& S7C). We then tested whether the grafted $\beta-$ hairpins confer higher affinity for $\mathrm{Cdil}^{\mathrm{Nlact}}$ and $\mathrm{Cdil}{ }^{\text {Ykris }}$ immunity proteins. The CdiA-CT ${ }_{011} \mathrm{EC} 869 / \mathrm{Ykris}$ chimera bound to Cdil ${ }^{\text {Ykris }}$ with about the same affinity as $\mathrm{Cdil}_{011}{ }^{\mathrm{EC} 869}$, but somewhat surprisingly this domain bound to $\mathrm{Cdil}^{\text {Nlact }}$ with $\sim 10$-fold higher affinity (Table 2). The CdiA-CT ${ }_{011}{ }^{\mathrm{EC} 869 / \mathrm{Nlact}}$ domain bound to $\mathrm{Cdil}^{\mathrm{Nlact}}$ with essentially the same affinity as for $\mathrm{Cdil}_{011}{ }^{\mathrm{EC} 869}$ and interacted with $\mathrm{Cdil}^{\text {Ykris }}$ with approximately 10 -fold lower affinity (Table 2 ).

\section{Structure of the MAC/Cdil ${ }_{\mathrm{o} 11}^{\mathrm{EC} 869}$ complex}

In principle, molecules that disrupt CdiA-CT/Cdil complexes should liberate the toxin domain and induce $\mathrm{CDI}^{+}$bacteria to undergo auto-inhibition. Nowick and coworkers have previously developed macrocyclic peptides containing $\delta$-linked ornithine turn units that adopt a $\beta$-hairpin conformation and should be suitable to disrupting the CdiA-CT/Cdil complex ${ }^{16 ; 17}$. To test the feasibility of this strategy, we designed a macrocyclic peptide (MAC) that mimics the $\beta$-hairpin of $\mathrm{CdiA}_{\mathrm{A}} \mathrm{CT}_{011}{ }^{\mathrm{EC} 869}$. The MAC peptide contains residues corresponding to Lys242 - Ser253 of CdiA-CT ${ }_{011}{ }^{\mathrm{EC} 869}$, which were connected through a $\delta$-linked ornithine residue (Fig. S1). Biolayer interferometry experiments failed to detect a binding interaction between MAC and $\mathrm{Cdil}_{011}{ }^{\mathrm{EC} 869}$; and the MAC peptide was unable to promote DNase activity when added in $\sim 10^{3}$-fold molar excess to the CdiA-CT/Cdil ${ }_{011}{ }^{\mathrm{EC} 869}$ complex in vitro (data not shown). Despite its low affinity for $\mathrm{Cdil}_{011}{ }^{\mathrm{EC} 869}$, we were able to crystallize the MAC peptide in complex with the immunity protein and solve the structure to $2.0 \AA$ resolution by molecular replacement (Fig. 8A). As anticipated, the MAC peptide forms a two-stranded $\beta$-sheet, though there are only four cross- 
strand $\mathrm{H}$-bonds compared to the five in the CdiA-CT/Cdil ${ }_{011}{ }^{\mathrm{EC} 869}$ complex. The ornithine turn creates a bulge that prevents formation of the fifth $\mathrm{H}$-bond (Fig. 8B). The MAC/Cdil ${ }_{011}{ }^{\mathrm{EC} 869}$ structure superimposes well with $\mathrm{Cdil}_{011}{ }^{\mathrm{EC} 869}$ ( $r$ sm of $0.437 \AA$ over all $\alpha$-carbons), though helix $\alpha 3^{*}$ is displaced 3.0 $\AA$ to create a slightly altered $\beta$-hairpin binding pocket (Fig. 8B). Five MAC peptide side-chains form $\mathrm{H}$-bonds or ion-pair interactions with the immunity protein, in contrast to the six direct interactions observed in the CdiA-CT/Cdil ${ }_{011}{ }^{E C 869}$ complex. In the CdiA-CT/Cdil ${ }_{011}{ }^{E C 869}$ complex, $\beta$-hairpin residue Ser247 interacts with the immunity protein. However, the corresponding Ser7 residue within the MAC peptide does not interact with $\mathrm{Cdil}_{011}{ }^{\mathrm{EC} 869}$ (Fig. 8C). Additionally, the side-chain conformation of MAC residue Arg10 is altered compared to that of Arg249 in the CdiA-CT/Cdil ${ }_{011}{ }^{\text {EC869 }}$ structure, resulting in a $\mathrm{H}$-bond interaction with the hydroxyl of Ser80 rather than the backbone carbonyl of Phe75 in the toxin/immunity structure. The MAC/Cdil ${ }_{011}{ }^{\mathrm{EC} 869}$ structure establishes that structure-based designed macrocyclic peptides can bind in the $\mathrm{Cdil}_{011}{ }^{\mathrm{EC} 869} \beta$-hairpin binding pocket (Fig. 8D), forming contacts that mimic those found in the CdiA-CT/Cdil complexes.

\section{Discussion}

CDI toxin/immunity protein pairs are diverse and comprise more than 100 distinct families. Even within a given family, there is considerable sequence variability suggesting that toxin/immunity protein families continue to evolve. This phenomenon is well illustrated by homologues of the CdiA$\mathrm{CT} / \mathrm{C}$ dil $_{011}{ }^{\mathrm{EC} 869}$ toxin/immunity protein pair. Alignment of 26 closely related toxin domains from this family reveals that nearly all of the secondary-structure elements are highly conserved (Fig. S3A). The obvious exception is the $\beta 4 / \beta 5$-hairpin, which mediates the $\beta$-augmentation interaction and is the least conserved element in the family. Loop L1 of the toxin domain is responsible for all other contacts with the immunity protein; but in contrast to the $\beta$-hairpin, this region is well conserved with five invariant residues (Arg189, Leu190, Pro19, Phe194 and Asp198). Although loop L1 is highly conserved, it interacts with immunity proteins using distinct contacts in the CdiA-CT/Cdil ${ }_{011}{ }^{\mathrm{EC} 869}$ and CdiA-CT/Cdil ${ }^{\text {YPIII }}$ complexes. Loop L1 of CdiA-CT ${ }_{011}{ }^{\mathrm{EC} 869}$ engages almost exclusively in hydrophobic and van der Waals interactions, whereas the $\mathrm{C}$-terminal portion of the $\mathrm{CdiA}-\mathrm{CT}^{\mathrm{YPIII}}$ loop is dominated by direct $\mathrm{H}$-bond and 
ion-pair interactions involving residues Asp201, Ala203 and Thr204. The differences are striking

because these three residues are also present in $\mathrm{CdiA}-\mathrm{CT}_{011}{ }^{\mathrm{EC} 869}$, yet do not form the same interactions. Similar phenomena are observed for the immunity proteins. Cdil strand $\beta 3^{*}$ anneals with the toxin's variable $\beta 5$ strand during $\beta$-augmentation; and accordingly $\beta 3^{*}$ varies between immunity proteins in the family (Fig. S3B). However, Cdil strands $\beta 7^{*}, \beta 8^{*}, \beta 9^{*}$ and the intervening loops are highly conserved, yet this region interacts with cognate toxins using distinct molecular contacts. In several instances, highly conserved residues engage in direct $\mathrm{H}$-bonds in one complex, but fail to make any intermolecular contact in another closely related complex. Therefore, even conserved sequence elements can be exploited to discriminate against near-cognate partners. The idiosyncratic nature of these interactions most likely explains why immunity-binding specificity cannot be switched through a simple exchange of $\beta 4 / \beta 5$-hairpins between homologous toxins.

The divergence of toxin/immunity protein interactions was first recognized and characterized in a subset of E-class colicins. Colicins are diffusible protein toxins released by some strains of $E$. coli to kill other competing bacteria ${ }^{18}$. Though colicins and $\mathrm{CdiA}$ proteins are not related, there are several features common to both competition systems. One striking parallel is the variability of C-terminal toxin domains. The eight characterized E-class colicins share nearly identical N-terminal domains, but their C-terminal nuclease domains are distinct with either DNase (E2, E7, E8 and E9), ribosomal RNase (E3, E4 and E6) or tRNase (E5) activities ${ }^{18}$. Like CdiA proteins, colicins are always encoded in tandem with a specific immunity protein that binds the nuclease domain and blocks its activity. Colicins E2, E7, E8 and E9 carry homologous DNase domains, yet their respective immunity proteins do not protect against near-cognate toxins ${ }^{19 ; 20}$. Structure-function analyses show that E-class immunity proteins bind to a contiguous stretch of $\sim 30$ residues that are highly variable between the different nuclease domains ${ }^{21 ; 22 ;}$ ${ }^{23}$. Similarly, the interaction surfaces on the immunity proteins are also variable, but contain a conserved core interaction comprised of Tyr54 and Tyr55 (ImE9 numbering) ${ }^{21 ; 24}$. This invariant core provides significant binding energy and near-cognate colicin toxin/immunity protein interactions often have dissociation constants of $10^{-8} \mathrm{M}^{25}$, which are similar in affinity to the cognate CdiA-CT/Cdil complexes studied here. An analogous core interaction centered at the tip of the $\beta$-hairpin is found in 
the CdiA-CT/Cdil ${ }_{011}{ }^{\mathrm{EC} 869}$ toxin/immunity family. Leu246 of the toxin engages in a hydrophobic interaction with an aliphatic residue in the immunity protein (Ala131 in Cdil $_{011}{ }^{\text {EC869 }}$ and Val141 in Cdil ${ }^{\text {YPIII }}$. Similarly, toxin residue Ser247 interacts with a Tyr residue (Tyr84 in Cdil $_{011}{ }^{\text {EC869 }}$ and Tyr94 in Cdil ${ }^{\text {YPIII }}$ ) that is invariant in the immunity protein family (Fig. S3B). However, these core interactions do not provide significant binding affinity for near-cognate toxin/immunity pairs. A final important parallel between the colicin E-class and CdiA-CT ${ }_{011}{ }^{\mathrm{EC} 869} \mathrm{DNases}$ is that the immunity proteins both bind to exosites, leaving the nuclease active site exposed in the toxin/immunity complex ${ }^{7 ; 18}$. The spatial segregation of substrate and immunity binding sites presumably provides the flexibility to evolve unique protein-protein interactions while retaining catalytic activity. The fact that two unrelated DNase toxin/immunity pairs appear to be diverging rapidly suggests that this is a general and perhaps universal feature of toxin/immunity systems.

Protein-protein interactions presumably evolve through mutational drift followed by reciprocal changes in the binding partner to maintain overall affinity while the underlying molecular contacts change. Riley and colleagues have proposed a diversification-selection model to explain the observed diversity in E-class colicin/immunity protein pairs. According to their model, some mutations expand immunity function and allow the newly evolved immunity protein to not only protect against its cognate toxin, but also against the colicins released by other strains ${ }^{26 ; 27}$. Such mutations would appear to be rare, but have been identified and characterized experimentally ${ }^{28 ;} 29$. One striking example that supports this model is the Asp33Leu mutation in ImE2 immunity protein, which increases affinity for non-cognate colicin E9 more than a 3,000-fold ${ }^{29}$. The advantage conferred by the new immunity gene would provide the selective pressure to retained the allele and allow it to become fixed in the population. This in turn allows for subsequent mutations in the linked colicin gene. Further mutations in the colicin are predicted to produce "super-killer" toxins, to which the ancestral bacteria are not immune ${ }^{27}$. Thus, the evolved colicin/immunity pair kills ancestral cells, thereby allowing fixation of the new pair in the population. Multiple iterations of this process are predicted to eventually produce a family of divergent toxin/immunity pairs. Of course, mutations that disrupt the toxin/immunity protein complex 
should be lethal to the cell, so the pressure to retain high-affinity interactions is presumably a significant barrier to diversification. However, colicin/immunity protein complexes have some of the highest known binding affinities, with cognate pairs characterized by femtomolar dissociation constants $22 ; 25 ; 29 ; 30$. Therefore, even if a mutation results in a 1000-fold decrease in affinity, the complex will still have a subnanomolar dissociation constant, which is sufficient to provide complete protection against toxicity ${ }^{25 ; 30}$. Thus, the extraordinarily high affinity of cognate colicin/immunity protein complexes provides a buffer against the potentially lethal effects of mutations that disrupt the toxin/immunity protein interface. In contrast, the CDI toxin/immunity proteins studied here have much lower binding affinities with dissociation constants of about $20 \mathrm{nM}$ for cognate pairs. Therefore, CDI toxin/immunity systems must exploit other biophysical mechanisms to avoid self-intoxication during evolution. One possible mechanism involves the over-expression of immunity proteins relative to the toxins. The majority (21 of 25) of CdiA-CT ${ }_{011}{ }^{\mathrm{EC} 869}$ homologues presented in Fig. S3A are encoded by truncated cdiA gene fragments that lack the $\mathrm{N}$-terminal coding sequences required for secretion. These pseudogene pairs are termed "orphan" modules, because they resemble cdiA-CT/cdil coding sequences that have been displaced from full-length cdiA genes ${ }^{9}$. Orphan $c d i A-C T$ reading frames usually lack translation initiation signals, whereas the linked orphan cdil genes have canonical ribosome-binding sites upstream of the initiating Met codon. These observations suggest that the toxins are expressed at very low levels, but the immunity proteins are highly expressed. Under these conditions, the selective pressure to retain immunity function would be relieved and allow the immunity gene to undergo drift without lethal consequences. This hypothetical scenario is supported by the observation that noncognate/mutated immunity proteins can fully protect cells when over-expressed ${ }^{25 ; 31}$. Therefore, we propose that the organization of $c d i A-C T / c d i l$ gene pairs into orphan modules serves to accelerate toxin/immunity evolution by attenuating toxin expression. We note that this could be a general strategy to generate diversity in inter-bacterial competition systems because similar clusters of orphan gene pairs are associated with rhs genes in type VI secretion systems ${ }^{9 ; 32}$ and the mafB genes of Neisseria species $^{33}$. 
CDI systems are widespread throughout proteobacteria and are most commonly found in pathogenic species, such as Yersinia pestis, Neisseria meningitidis and Burkholderia pseudomallei ${ }^{2 ; 34}$. Because $\mathrm{CDI}^{+}$bacteria exchange CdiA-CT toxins with one another, it may be possible to induce bacterial suicide with small molecules that specifically disrupt CDI toxin/immunity protein binding interactions. The $\beta$-hairpin binding pocket within $\mathrm{Cdil}_{011}{ }^{\mathrm{EC} 869}$ and homologous immunity proteins is an attractive target to test this antimicrobial strategy. Small cyclic peptides that fold into $\beta$-hairpins have been used to study protein-protein and protein-DNA interactions and in some instances have been used to specifically disrupt protein complexes ${ }^{35,36}$. As illustrated by the MAC/Cdil ${ }_{011}{ }^{\mathrm{EC} 869}$ structure, cyclic $\beta$-hairpin mimics can be designed to bind Cdil immunity proteins. Our design could be improved to enhance binding affinity and possibly be utilized as a protein-protein complex inhibitor by increasing the number of residues or designing additional contacts. Although the current MAC contains pentapeptide strands, we have previously reported cyclic $\beta$-hairpin mimics containing heptapeptide and nonapeptide $\beta$-strands ${ }^{37 ; 38}$. Homologous MACs containing larger $\beta$-hairpin mimics and designed to achieve more contacts may allow rational design of a higher affinity macrocyclic peptide that specifically may disrupt toxin/immunity complexes within bacterial pathogens, setting the stage for the development of a new class of antibacterials.

\section{Materials and Methods}

\section{Bacterial strains and plasmid constructs}

All bacterial strains and plasmids used in this study are presented in Table S2. All primers used in this study are presented in Table S3. Yellow fluorescent protein (YFP)-labeled E. coli EPI100 cells were generated by integrating the $y f p$ coding sequence at the gal locus. First, a genomic integration construct was made by amplifying the kanamycin-resistance cassette from plasmid pKAN ${ }^{39}$ with primers Kan-1/Kan-2, followed by blunt-end ligation to Smal-digested plasmid pBluescript. One plasmid clone was identified with the kanamycin-resistance cassette in the opposite orientation as pKAN, and this plasmid was termed pNAK. A fragment of galM was then amplified using primers $\mathrm{CH} 3789 / \mathrm{CH} 3790$, and the product ligated to Sacl/BamHI-digested plasmid pNAK to produce pCH2500. A yfp-galT 
fragment was amplified from E. coli DA28100 (a gift from Sanna Koskiniemi, Uppsala University) using primers $\mathrm{CH} 3787 / \mathrm{CH} 3788$, digested with $\mathrm{Kpnl} / \mathrm{EcoRI}$, then ligated into $\mathrm{pCH} 2500$ to yield plasmid $\mathrm{pCH} 2503$. The large $\mathrm{Kpnl} / \mathrm{Sacl}$ fragment from $\mathrm{pCH} 2503$ was recombined into E. coli EPI100 cells that harbor plasmid pSIM6 as described ${ }^{40 ; 41}$. mKate2-labeled target bacteria were generating by integrating the coding sequence of mKate2 at the phage HK022 attP site using plasmids pDE1013 and pAH69 as described previously ${ }^{42}$.

The coding sequence for CdiA-CT/Cdil ${ }^{\text {YPIII }}$ was amplified from Y. pseudotuberculosis YPIII genomic DNA with primers YPK0575-Kpn-for/YPK0576-Xho-rev. The resulting product was digested with $\mathrm{Kpnl} / \mathrm{Xhol}$ and ligated $\mathrm{pET} 21 \mathrm{~S}$ to generate plasmid $\mathrm{pCH} 10413$. The $\mathrm{CdiA}-\mathrm{CT}_{011}{ }^{\mathrm{EC} 869 / \Delta \beta 4 \beta 5}$ expression construct was generated by replacing the $\beta 4 / \beta 5$-hairpin coding sequence with a Gly-Ser linker. The $5^{\prime}$-end of the construct was amplified with primers $\beta$-deletion-for $1 / \beta$-deletion-rev1 and the $3^{\prime}-$ end with primers $\beta$-deletion-for2/ $\beta$-deletion-rev2. The two PCR fragments were ligated at the BamHI site, and the joined fragments re-amplified with $\beta$-deletion-for $1 / \beta$-deletion-rev2. The resulting product was ligated to $\mathrm{pET} 21 \mathrm{~d}$ using $\mathrm{Ncol}$ and $\mathrm{Xhol}$ restriction sites to generate $\mathrm{pCH} 10369$. Catalytically inactive CdiA-CT ${ }_{011}{ }^{\mathrm{EC} 869}$ domains carrying the Asp198Ala mutation and heterologous $\beta$-hairpin sequences were generated by PCR. Plasmid pCH10164 was amplified with primers EC869-CTNco/EC869-Nlact(beta)-rev and EC869-Nlact(beta)-for/EC869-cdil-Spe, and the two products combined by overlap extension PCR (OE-PCR) ${ }^{43}$ using primers EC869-CT-Nco/EC869-cdil-Spe. The final product was digested with $\mathrm{Ncol} / \mathrm{Spel}$ and ligated to $\mathrm{pET} 21 \mathrm{~S}$ to generate plasmid $\mathrm{pCH} 10365$. The same procedure was used to introduce the Y. kristensenii $\beta$-hairpin by PCR with primers EC869-CTNco/EC869-Ykris(beta)-rev and EC869-Ykris (beta)-for/EC869-cdil-Spe. The two products were combined by OE-PCR and ligated to $\mathrm{pET} 21 \mathrm{~S}$ to generate plasmid $\mathrm{pCH} 10175$. The coding sequences for Cdil ${ }^{\text {Ykris }}$ (ykris0001_10740) and Cdil ${ }^{\text {Nlact }}$ (NEILACOT_05636) were chemically synthesized (Genscript, Inc.) with flanking restriction sites and ligated to plasmid pUC57. The ykris0001_10740 sequence was sub-cloned into $\mathrm{pTrc99KX}$ to generate plasmid $\mathrm{pCH} 10103$, which was then used as a template for PCR with primers pTrc-seq2/Ykris-cdil-Spe-rev. The resulting product was digested with Kpnl/Spel and ligated to pET21K to generate plasmid pCH10170. The NEILACOT_05636 sequence 
was subcloned into $\mathrm{pCH} 450$ to generate plasmid $\mathrm{pCH} 10101$, which was then used as a template for PCR with primers $\mathrm{pCH} 450$-for/Nlact-cdil-Spe-rev. The resulting product was digested with Ncol/Spel and ligated to $\mathrm{pET} 21 \mathrm{~S}$ to generate plasmid $\mathrm{pCH} 10172$.

The chimeric CDI system that deploys CdiA-CT ${ }^{\mathrm{YPIII}}$ toxin was generated by replacing the CdiA$\mathrm{CT}_{011}{ }^{\mathrm{EC} 869} \mathrm{DNase}$ domain with the corresponding region of $\mathrm{CdiA}-\mathrm{C} T^{\mathrm{YPIII}}$. Regions upstream and downstream of the $c$ diA-CT/cdil ${ }_{011}{ }^{\mathrm{EC} 869}$ sequence were amplified from plasmid $\mathrm{pCH} 9305$ using primers DL1527/EC869011-G173-rev (upstream) and EC93-YPIII-down-for/DL2368 (downstream). The cdiACT/cdil ${ }^{\text {YPIII }}$ sequence was amplified from Y. pseudotuberculosis YPIII genomic DNA using primers EC869o11-G173-for/EC93-YPIII-chim-rev. The three PCR products were combined by OE-PCR using primers DL1527/DL2368. The final product was electroporated together with plasmid pCH10163 into E. coli strain DY378 as described ${ }^{7 ; 8}$. Recombinants were selected on yeast extract/glucose-agar supplemented with $33 \mu \mathrm{g} / \mathrm{mL}$ chloramphenicol and $10 \mathrm{M} \mathrm{D/L-o-chlorophenylalanine.} \mathrm{All} \mathrm{plasmid}$ constructs were verified by DNA sequence analysis.

\section{Protein purification}

All proteins were over-produced from pET21-derived plasmid using either E. coli $\mathrm{CH} 2016$ or $E$. coli BL21-Gold(DE3). Cells were grown aerobically at $37^{\circ} \mathrm{C}$ in LB medium containing $150 \mu \mathrm{g} / \mathrm{mL}$ ampicillin. CdiA-CT/Cdil ${ }^{\text {YPIII }}$ expression was induced by the addition of $1 \mathrm{mM}$ isopropyl- $\beta-\mathrm{D}$ thiogalactoside at an $\mathrm{OD}_{600} \sim 0.8$ and grown for a further $3-4 \mathrm{~h}$ before harvesting. Cells were collected by centrifugation at $5,500 \times g$ for $25 \mathrm{~min}$ and then washed with resuspension buffer [20 $\mathrm{mM}$ sodium phosphate ( $\mathrm{pH} 7.0), 150 \mathrm{mM} \mathrm{NaCl}$. Cells were resuspended and disrupted by sonication on ice in resuspension buffer containing $10 \mathrm{mg} / \mathrm{mL}$ lysozyme and $1 \mathrm{mM}$ phenylmethylsulfonyl fluoride. Cell debris was removed by centrifugation at $18,000 \times g$ for $30 \mathrm{~min}$ followed by filtration through a $1.0 \mu \mathrm{m}$ filter. Clarified lysates were loaded onto a $\mathrm{Ni}^{2+}$-charged HiTrap column ( $5 \mathrm{~mL}$; GE Healthcare) or $\mathrm{Ni}^{2+}{ }_{-}$ nitrilotriacetic acid $\left(\mathrm{Ni}^{2+}-\mathrm{NTA}\right)$ agarose resin $(\mathrm{MCLAB})$ and washed with resuspension buffer supplemented with $10 \mathrm{mM}$ imidazole. Proteins were eluted with a linear gradient of imidazole $(10-500$ $\mathrm{mM}$ ) in resuspension buffer. Fractions were collected, combined, and concentrated to a volume of $\sim 500$ 
$\mu \mathrm{L}$ using a 10-kDa centrifugal concentrator (Centricon; Millipore). Proteins were further purified by gel filtration on a Superdex 200 column for the CdiA-CT/Cdil ${ }^{\text {YPIII }}$ complex or Superdex 75 for individual immunity proteins (GE Healthcare). Gel filtration columns were equilibrated with $20 \mathrm{mM}$ sodium phosphate (pH 7.0), $150 \mathrm{mM} \mathrm{NaCl}$ using an AKTA FPLC. Purification of Cdil ${ }^{\text {Ykris }}$ and Cdil ${ }_{011}^{\text {EC869 }}$ followed the same protocol, except all buffers contained $20 \mathrm{mM}$ Tris- $\mathrm{HCl}(\mathrm{pH} 7.4)$ instead of sodium phosphate. CdiA-CT/Cdil ${ }^{\text {YPIII }}$, Cdil $^{\text {Ykris }}$, and $\mathrm{Cdil}_{011}{ }^{\mathrm{EC} 869}$ were concentrated to $10,12.5$ and $7.5 \mathrm{mg} / \mathrm{mL}$ (respectively) for crystallization trials.

The individual $\mathrm{His}_{6}$-tagged Cdil proteins were over-produced from plasmid pET21d constructs and purified as described above for $\mathrm{Cdil}_{\mathrm{0} 11}{ }^{\mathrm{EC} 869}$. CdiA-CT proteins were isolated from co-expressed $\mathrm{His}_{6}$-tagged Cdil proteins by two methods, depending on whether the two proteins co-eluted following $\mathrm{Ni}^{2+}$-affinity chromatography. CdiA-CT/Cdil-His ${ }_{6}$ complexes were denatured overnight in $6 \mathrm{M}$ urea and then subjected to $\mathrm{Ni}^{2+}$-affinity chromatography in buffers containing $6 \mathrm{M}$ urea. Denatured CdiA-CT toxins were collected from the void volume, refolded by dialysis into $20 \mathrm{mM}$ Tris- $\mathrm{HCl}(\mathrm{pH} 8.0), 10 \mathrm{mM}$ $\mathrm{NaCl}$, then concentrated on a HiTrap Q anion-exchange column and eluted with a salt gradient, yielding 95\% pure CdiA-CT protein. Purified toxins were then exchanged into $20 \mathrm{mM}$ Tris- $\mathrm{HCl}(\mathrm{pH} 7.4), 150 \mathrm{mM}$ $\mathrm{NaCl}$ by gel filtration on a $\mathrm{S} 75$ column.

\section{Crystallization and structure determination}

Protein crystals were grown by hanging-drop vapor diffusion, with drops containing a 1:1 ratio (vol/vol) of protein solution to reservoir liquor. Crystals were mounted and collected under cryoconditions with the addition of $40 \%$ glycerol as cryoprotectant to the reservoir solution. Datasets were collected at $70 \mathrm{~K}$ at a wavelength of $1.0 \AA$ and images were indexed, integrated and reduced using either iMOSFLM (CdiA-CT/Cdil ${ }^{\text {YPIII }}$ complex) ${ }^{44}$ or the HKL2000 suite (Cdil ${ }^{\text {Ykris }}$ and MAC/Cdil ${ }{ }^{\text {EC869 }}{ }^{45}$. Initial phases were determined by molecular replacement by autoMR in PHENIX using the CdiA$\mathrm{CT} / \mathrm{C}$ dil $_{011}{ }^{\mathrm{EC} 869}$ structure (PDB: 4G6U) as a search model. Initial model building was performed by Autobuild in PHENIX. The final models were built through iterative manual building in Coot and refined 
with phenix.refine. Data collection and refinement statistics are presented in Table 1. All molecular graphics were prepared with PyMOL ${ }^{46}$.

CdiA-CT/Cdil ${ }^{\text {YPIII }}$ crystals were grown from a $10 \mathrm{mg} / \mathrm{mL}$ solution and a reservoir containing 50 mM HEPES (pH 7.0), 20\% PEG 3350, 1\% tryptone. The complex crystallized in space group C2 with unit cell dimensions $65.51 \AA \times 65.51 \AA \times 71.49 \AA$ and one complex per asymmetric unit. The model contains residues Met174 - Lys297 (numbered from Val1 of the VENN motif) of CdiA-CT ${ }^{\text {YIII }}$ and residues Asp3 - Lys176 of Cdil ${ }^{\text {YPIII }}$. CdiA-CT ${ }^{\text {YPIII }}$ residues Lys182, Lys220, Lys240 and Lys297 were modeled as Ala due to lack of observable side-chain density. Similarly, Cdil ${ }^{\text {YPIII }}$ residues Asp3, Lys108, Lys118, Lys148 and Lys176 were modeled as Ala residues. The final CdiA-CT/Cdil ${ }^{\text {YPIII }}$ model includes 148 water molecules resulting in an $R_{\text {work }} / R_{\text {free }}(\%)$ of $20.5 / 25.6$ (Table 1). Cdil ${ }^{Y k r i s}$ immunity protein crystals were grown from a $12.5 \mathrm{mg} / \mathrm{mL}$ solution over a reservoir containing $0.2 \mathrm{M}$ ammonium fluoride, 20\% PEG 3350. The crystal space group was P3 1 with unit cell dimensions $54.448 \AA \times 54.448 \AA \times$ 54.472 $\AA$ and one molecule per asymmetric unit. The final model contains Cdil ${ }^{\text {Ykris }}$ residues Met1 Gly165 and 130 water molecules resulting in an $R_{\text {work }} / R_{\text {free }}(\%)$ of $18.1 / 22.1$. Cdil ${ }^{\text {Ykris }}$ residues Lys4, Glu67, Lys96, Lys126 and Lys136 were modeled as Ala due to lack of observable side-chain density. In

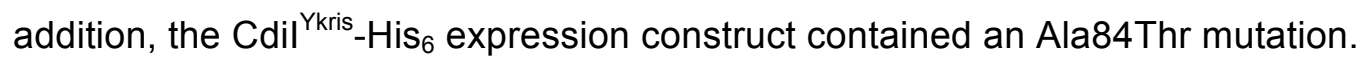

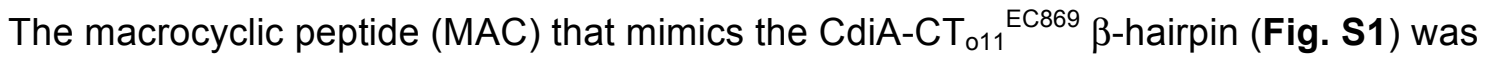
prepared according to previously described procedures ${ }^{16 ; 47 ; 48}$. MAC peptide (2 mg) was added to 200 $\mu \mathrm{L}$ of $7.5 \mathrm{mg} / \mathrm{mL} \mathrm{Cdil}_{011}{ }^{\mathrm{EC} 869}$ to yield a solution at a $\sim 10: 1$ peptide:protein ratio. MAC/Cdil ${ }_{011}{ }^{\mathrm{EC} 869}$ Cocrystals were grown over two days in $0.2 \mathrm{M}$ sodium acetate ( $\mathrm{pH} 5.6), 0.1 \mathrm{M}$ bis-tris propane, $\mathrm{pH} 6.9$, and $20 \%$ (wt/vol) PEG 3350, using the protein/peptide mixture described. Initial crystals were of poor quality and resulted in highly mosaic diffraction data. Crystal quality was improved by microseeding ${ }^{49}$. Briefly, crystals were harvested into $80 \mu \mathrm{L}$ of crystallization solution and a seed stock was generated using a seed bead (Hampton). Following optimization, suitable diffraction quality crystals were generated using a hanging drop containing $1 \mu \mathrm{L}$ of seed stock and $1 \mu \mathrm{L}$ of the protein/peptide mixture following a three-fold dilution. The MAC/Cdil ${ }_{011}{ }^{\mathrm{EC} 869}$ complex crystallized in space group $\mathrm{P} 2{ }_{1}$ with unit cell dimensions $34.776 \AA \times 128.166 \AA \times 44.953 \AA$ (Table 1). Each asymmetric unit contained two 
MAC/Cdil ${ }_{011}{ }^{\mathrm{EC} 869}$ complexes. The final model contains two molecules of Cdil ${ }_{011}{ }^{\mathrm{EC} 869}$ residues Ala2 Gly167, two macrocyclic peptides and 132 water molecules, resulting in $R_{\text {work }} / R_{\text {free }}(\%)$ of $18.4 / 23.1$. Residues Lys5, GIn43, Glu78, Lys85, Glu93 of one Cdil ${ }_{011}{ }^{\text {EC869 }}$ molecule (chain D only), Asp117 and Glu139 of both Cdil $_{011}{ }^{\mathrm{EC} 869}$ molecules were modeled as Ala due to lack of observable side-chain density.

\section{Protein analyses}

The secondary structure of purified toxins $(0.1 \mathrm{mg} / \mathrm{mL}$ in $20 \mathrm{mM}$ Tris- $\mathrm{HCl}, \mathrm{pH} 7.4)$ was analyzed by CD spectroscopy on a Jasco J-720 spectropolarimeter using a $0.1 \mathrm{~cm}$ path-length. Spectra were collected at $20 \mathrm{~nm} / \mathrm{min}$ with a $2 \mathrm{~nm}$ bandwidth and $4 \mathrm{~s}$ response time. Three consecutive scans were collected and averaged for each analysis. CdiA-CT/Cdil binding affinities were determined by biolayer interferometry as described previously ${ }^{7}$. Binding reactions were performed at $25^{\circ} \mathrm{C}$ in $20 \mathrm{mM}$ Tris- $\mathrm{HCl}$ $\left(\mathrm{pH}\right.$ 7.4), $150 \mathrm{mM} \mathrm{NaCl}$. Cdil-His ${ }_{6}$ immunity proteins were immobilized onto $\mathrm{Ni}^{2+}-\mathrm{NTA}^{2}$ biosensors and exposed to cognate or heterologous CdiA-CT toxins at $0.5-300 \mu \mathrm{M}$. A reference was subtracted from all binding curves before curve fitting. Curve fitting and data processing were performed using BLitz Pro software (ForteBio Inc.).

\section{In vitro analysis of nuclease activities}

The activity of purified CdiA-CT ${ }_{011}{ }^{\mathrm{EC} 869}$ and $\mathrm{CdiA}-\mathrm{CT}^{\mathrm{YPIII}}$ were assayed in vitro using supercoiled plasmid pUC18 as a substrate. CdiA-CT (at $1 \mu \mathrm{M}$ final concentration) was incubated with $250 \mathrm{ng}$ of plasmid DNA in $20 \mathrm{mM}$ Tris- $\mathrm{HCl}(\mathrm{pH} 7.5), 100 \mathrm{mM} \mathrm{NaCl}, 0.1 \mathrm{mg} / \mathrm{mL}$ bovine serum albumin supplemented with $2 \mathrm{mM} \mathrm{MgCl}_{2}$ or $\mathrm{ZnCl}_{2}$ for $1 \mathrm{~h}$ at $37^{\circ} \mathrm{C}$. Where indicated, purified Cdil-His 6 proteins were included at $2 \mu \mathrm{M}$ final concentration and allowed to bind CdiA-CT for 30 min at room temperature prior to adding substrate DNA. Reactions were quenched with $10 \mathrm{mM}$ EDTA followed by the addition of $300 \mu \mathrm{L}$ of denaturing solution (4 M guanidine- $\mathrm{HCl}, 33 \%$ 2-propanol). The reactions were purified over silica membrane spin columns (Epoch Life Sciences). Columns were then washed with 70\% ethanol, 
$10 \mathrm{mM}$ Tris- $\mathrm{HCl}(\mathrm{pH} 8.0)$ followed by elution with $10 \mathrm{mM}$ Tris- $\mathrm{HCl}(\mathrm{pH}$ 8.0). Purified DNA from reactions was run on 1\% agarose gels containing ethidium bromide and visualized using Bio-Rad Gel Doc 2000.

\section{Competition co-cultures and fluorescence microscopy}

Inhibitor cells (E. coli EPI100 carrying plasmids pCH9305, pCH2409 or pDAL878) and target cells (CH8251 carrying plasmids pTrc99a, pCH9315 or pCH848) were grown individually in LB media with $33 \mu \mathrm{g} / \mu \mathrm{L} \mathrm{Cm}$ for inhibitors and $150 \mu \mathrm{g} / \mu \mathrm{L}$ Amp for targets. The overnight cultures were diluted into fresh LB medium without antibiotics and grown in baffled flasks at $37^{\circ} \mathrm{C}$. At mid-log phase, the inhibitor and target strains were mixed together at a 1:1 ratio in baffled flasks and a sample was withdrawn to score viable target cells as colony forming units (cfu) per $\mathrm{mL}$ on LB-agar supplemented with $200 \mu \mathrm{g} / \mathrm{mL}$ rifampicin (Rif). After four hours of co-culture, another sample was taken and viable target cells enumerated on Rif-supplemented LB agar. Viable target cell counts are the mean cfu/mL \pm the standard error of the mean for three independent experiments. Competitions with fluorescent inhibitor and target bacteria were conducted as described above, except YFP-labeled inhibitor $\mathrm{CH} 2550$ cells and mKate2-labeled targets cells were used. Cells were diluted into fresh LB medium and grown to late log phase at $30^{\circ} \mathrm{C}$ in the dark to maximize fluorescence. Inhibitor and target cells were mixed at a $1: 1$ ratio in baffled flasks and incubated at $37^{\circ} \mathrm{C}$ with shaking in the dark for the duration of the experiment. Samples (equivalent to $O D_{600}=0.2$ ) were removed at the indicated times and cells were collected by centrifugation. Cells were briefly resuspended in freshly prepared $4 \%$ formaldehyde in $1 \times$ phosphate buffered saline (PBS), and the fixation reaction quenched with $125 \mathrm{mM}$ glycine. Fixed cells were washed with $1 \times$ PBS and spotted onto a poly-D-lysine coated slide (Gold Seal Fluorescent Antibody Rite-On Slides from Fisher prepared by coating with a $1 \%$ poly-D-lysine solution prior to addition of cells). Unbound cells were removed gently with Nanopure water, and the slides treated with Fluorogel II with DAPI mounting medium (Fisher Scientific/EMS) and a coverslip was overlaid prior to imaging. Images were acquired on an Olympus fluorescent microscope with a $100 \times$ oil objective using an Optronics MacroFire digital microscope camera. Lightfield images were captured with a $12 \mathrm{~ms}$ exposure (gain 2) and DAPI images were acquired in grayscale with a 48 ms exposure (gain 2). 
Fluorescent images were captured in grayscale using a $502 \mathrm{~ms}$ exposure/gain 5 (for YFP) or a $1 \mathrm{~s}$ exposure/gain 5 (for mKate2). Images were overlaid and false-colored using $\mathrm{FIJI}^{50}$, and stacked images were cropped to $400 \times 400$ pixels using GIMP. The same microscope images used to display fluorescence were used to obtain cell length measurements. Cells were manually measured using the line tool in FIJI, and between 175 and 328 cells from three microscopy fields were measured for each co-culture competition. Each object plotted represents a single cell length measurement. $P$ values were obtained using two-tailed unpaired t-tests.

\section{Accession numbers}

Coordinates and structure factors have been deposited in the Protein Data Bank with accession numbers 4ZQU, 4ZQV and 4ZQW.

\section{Acknowledgments}

This research was supported by the National Institutes of Health (GM102318 to C.S.H. and C.W.G); and the National Science Foundation (CHE-1058825 to J.S.N. and DGE-1144085 to J.L.E.W.). Structure determination was, in part, supported by the Advanced Light Source (U.S. Department of Energy under Contract No. DE-AC02-05CH11231) at Berkeley National Laboratories, and The Stanford Synchrotron Radiation Lightsource (supported in part by National Institutes of Health P41 GM103393 and U.S. Department of Energy DE-AC02-76SF00515). Funding for open access charge: National Institutes of Health. We would like to tank the staff at ALS and SSRL for their invaluable help in data collection. We would also like to thank Elias Gerrick and Sonya Donato for technical support. The funders had no role in study design, data collection and analysis, decision to publish, or preparation of the manuscript.

\section{References}

1. Aoki, S. K., Pamma, R., Hernday, A. D., Bickham, J. E., Braaten, B. A. \& Low, D. A. (2005). Contact-dependent inhibition of growth in Escherichia coli. Science 309, 1245-8. 
2. Aoki, S. K., Diner, E. J., de Roodenbeke, C. T., Burgess, B. R., Poole, S. J., Braaten, B. A., Jones, A. M., Webb, J. S., Hayes, C. S., Cotter, P. A. \& Low, D. A. (2010). A widespread family of polymorphic contact-dependent toxin delivery systems in bacteria. Nature 468, 439-42.

3. Aoki, S. K., Malinverni, J. C., Jacoby, K., Thomas, B., Pamma, R., Trinh, B. N., Remers, S., Webb, J., Braaten, B. A., Silhavy, T. J. \& Low, D. A. (2008). Contact-dependent growth inhibition requires the essential outer membrane protein BamA (YaeT) as the receptor and the inner membrane transport protein AcrB. Mol Microbiol 70, 323-40.

4. Ruhe, Z. C., Wallace, A. B., Low, D. A. \& Hayes, C. S. (2013). Receptor polymorphism restricts contact-dependent growth inhibition to members of the same species. mBio 4, e00480-13.

5. Webb, J. S., Nikolakakis, K. C., Willett, J. L., Aoki, S. K., Hayes, C. S. \& Low, D. A. (2013). Delivery of CdiA nuclease toxins into target cells during contact-dependent growth inhibition. PLOS ONE 8, e57609.

6. Aoki, S. K., Webb, J. S., Braaten, B. A. \& Low, D. A. (2009). Contact-dependent growth inhibition causes reversible metabolic downregulation in Escherichia coli. J Bacteriol 191, 177786.

7. Morse, R. P., Nikolakakis, K. C., Willett, J. L., Gerrick, E., Low, D. A., Hayes, C. S. \& Goulding, C. W. (2012). Structural basis of toxicity and immunity in contact-dependent growth inhibition (CDI) systems. Proc Natl Acad Sci U S A 109, 21480-5.

8. Beck, C. M., Morse, R. P., Cunningham, D. A., Iniguez, A., Low, D. A., Goulding, C. W. \& Hayes, C. S. (2014). CdiA from Enterobacter cloacae delivers a toxic ribosomal RNase into target bacteria. Structure 22, 707-18.

9. Poole, S. J., Diner, E. J., Aoki, S. K., Braaten, B. A., t'Kint de Roodenbeke, C., Low, D. A. \& Hayes, C. S. (2011). Identification of functional toxin/immunity genes linked to contactdependent growth inhibition (CDI) and rearrangement hotspot (Rhs) systems. PLoS Genet 7 , e1002217.

10. Zhang, D., de Souza, R. F., Anantharaman, V., Iyer, L. M. \& Aravind, L. (2012). Polymorphic toxin systems: Comprehensive characterization of trafficking modes, processing, mechanisms of action, immunity and ecology using comparative genomics. Biol Direct 7, 18.

11. Nikolakakis, K., Amber, S., Wilbur, J. S., Diner, E. J., Aoki, S. K., Poole, S. J., Tuanyok, A., Keim, P. S., Peacock, S., Hayes, C. S. \& Low, D. A. (2012). The toxin/immunity network of Burkholderia pseudomallei contact-dependent growth inhibition (CDI) systems. Mol Microbiol 84, 516-29.

12. Carr, S., Walker, D., James, R., Kleanthous, C. \& Hemmings, A. M. (2000). Inhibition of a ribosome-inactivating ribonuclease: the crystal structure of the cytotoxic domain of colicin E3 in complex with its immunity protein. Structure 8, 949-60. 
13. Soelaiman, S., Jakes, K., Wu, N., Li, C. \& Shoham, M. (2001). Crystal structure of colicin E3: implications for cell entry and ribosome inactivation. Mol Cell 8, 1053-62.

14. Gioia, U., Laneve, P., Dlakic, M., Arceci, M., Bozzoni, I. \& Caffarelli, E. (2005). Functional characterization of XendoU, the endoribonuclease involved in small nucleolar RNA biosynthesis. J Biol Chem 280, 18996-9002.

15. Renzi, F., Caffarelli, E., Laneve, P., Bozzoni, I., Brunori, M. \& Vallone, B. (2006). The structure of the endoribonuclease XendoU: From small nucleolar RNA processing to severe acute respiratory syndrome coronavirus replication. Proc Natl Acad Sci U S A 103, 12365-70.

16. Woods, R. J., Brower, J. O., Castellanos, E., Hashemzadeh, M., Khakshoor, O., Russu, W. A. \& Nowick, J. S. (2007). Cyclic modular beta-sheets. J Am Chem Soc 129, 2548-58.

17. Nowick, J. S. \& Brower, J. O. (2003). A new turn structure for the formation of beta-hairpins in peptides. J Am Chem Soc 125, 876-7.

18. Cascales, E., Buchanan, S. K., Duche, D., Kleanthous, C., Lloubes, R., Postle, K., Riley, M., Slatin, S. \& Cavard, D. (2007). Colicin biology. Microbiol Mol Biol Rev 71, 158-229.

19. Cooper, P. C. \& James, R. (1984). Two new E colicins, E8 and E9, produced by a strain of Escherichia coli. J Gen Microbiol 130, 209-15.

20. Watson, R., Rowsome, W., Tsao, J. \& Visentin, L. P. (1981). Identification and characterization of Col plasmids from classical colicin E-producing strains. J Bacteriol 147, 569-77.

21. Kleanthous, C., Kuhlmann, U. C., Pommer, A. J., Ferguson, N., Radford, S. E., Moore, G. R., James, R. \& Hemmings, A. M. (1999). Structural and mechanistic basis of immunity toward endonuclease colicins. Nat Struct Biol 6, 243-52.

22. Wojdyla, J. A., Fleishman, S. J., Baker, D. \& Kleanthous, C. (2012). Structure of the ultra-highaffinity colicin E2 DNase--Im2 complex. J Mol Biol 417, 79-94.

23. Ko, T. P., Liao, C. C., Ku, W. Y., Chak, K. F. \& Yuan, H. S. (1999). The crystal structure of the DNase domain of colicin E7 in complex with its inhibitor $\operatorname{Im} 7$ protein. Structure 7, 91-102.

24. Kleanthous, C. \& Walker, D. (2001). Immunity proteins: enzyme inhibitors that avoid the active site. Trends Biochem Sci 26, 624-31.

25. Li, W., Keeble, A. H., Giffard, C., James, R., Moore, G. R. \& Kleanthous, C. (2004). Highly discriminating protein-protein interaction specificities in the context of a conserved binding energy hotspot. J Mol Biol 337, 743-59.

26. Riley, M. A. (1993). Positive selection for colicin diversity in bacteria. Mol Biol Evol 10, 1048-59.

27. Tan, Y. \& Riley, M. A. (1997). Positive selection and recombination: major molecular mechanisms in colicin diversification. Trends Ecol Evol 12, 348-51.

28. Masaki, H., Akutsu, A., Uozumi, T. \& Ohta, T. (1991). Identification of a unique specificity determinant of the colicin E3 immunity protein. Gene 107, 133-8. 
29. Li, W., Hamill, S. J., Hemmings, A. M., Moore, G. R., James, R. \& Kleanthous, C. (1998). Dual recognition and the role of specificity-determining residues in colicin E9 DNase-immunity protein interactions. Biochemistry 37, 11771-9.

30. Wallis, R., Leung, K. Y., Pommer, A. J., Videler, H., Moore, G. R., James, R. \& Kleanthous, C. (1995). Protein-protein interactions in colicin E9 DNase-immunity protein complexes. 2. Cognate and noncognate interactions that span the millimolar to femtomolar affinity range. Biochemistry 34, 13751-9.

31. Levin, K. B., Dym, O., Albeck, S., Magdassi, S., Keeble, A. H., Kleanthous, C. \& Tawfik, D. S. (2009). Following evolutionary paths to protein-protein interactions with high affinity and selectivity. Nat Struct Mol Biol 16, 1049-55.

32. Koskiniemi, S., Garza-Sanchez, F., Sandegren, L., Webb, J. S., Braaten, B. A., Poole, S. J., Andersson, D. I., Hayes, C. S. \& Low, D. A. (2014). Selection of orphan Rhs toxin expression in evolved Salmonella enterica serovar Typhimurium. PLoS Genet 10, e1004255.

33. Jamet, A., Jousset, A. B., Euphrasie, D., Mukorako, P., Boucharlat, A., Ducousso, A., Charbit, A. \& Nassif, X. (2015). A new family of secreted toxins in pathogenic Neisseria species. PLoS Pathog 11, e1004592.

34. Ruhe, Z. C., Low, D. A. \& Hayes, C. S. (2013). Bacterial contact-dependent growth inhibition. Trends Microbiol 21, 230-7.

35. Loughlin, W. A., Tyndall, J. D., Glenn, M. P. \& Fairlie, D. P. (2004). Beta-strand mimetics. Chem Rev 104, 6085-117.

36. Fasan, R., Dias, R. L., Moehle, K., Zerbe, O., Vrijbloed, J. W., Obrecht, D. \& Robinson, J. A. (2004). Using a beta-hairpin to mimic an alpha-helix: cyclic peptidomimetic inhibitors of the p53HDM2 protein-protein interaction. Angew Chem Int Ed Engl 43, 2109-12.

37. Cheng, P. N., Liu, C., Zhao, M., Eisenberg, D. \& Nowick, J. S. (2012). Amyloid beta-sheet mimics that antagonize protein aggregation and reduce amyloid toxicity. Nat Chem 4, 927-33.

38. Pham, J. D., Chim, N., Goulding, C. W. \& Nowick, J. S. (2013). Structures of oligomers of a peptide from beta-amyloid. J Am Chem Soc 135, 12460-7.

39. Hayes, C. S., Bose, B. \& Sauer, R. T. (2002). Proline residues at the C terminus of nascent chains induce SsrA tagging during translation termination. J Biol Chem 277, 33825-32.

40. Datta, S., Costantino, N. \& Court, D. L. (2006). A set of recombineering plasmids for gramnegative bacteria. Gene 379, 109-15.

41. Thomason, L., Court, D. L., Bubunenko, M., Costantino, N., Wilson, H., Datta, S. \& Oppenheim, A. (2007). Recombineering: genetic engineering in bacteria using homologous recombination. Curr Protoc Mol Biol Chapter 1, Unit 116.

42. Bonnet, J., Subsoontorn, P. \& Endy, D. (2012). Rewritable digital data storage in live cells via engineered control of recombination directionality. Proc Natl Acad Sci U S A 109, 8884-9. 
43. Aiyar, A., Xiang, Y. \& Leis, J. (1996). Site-directed mutagenesis using overlap extension PCR. Methods Mol Biol 57, 177-91.

44. Battye, T. G., Kontogiannis, L., Johnson, O., Powell, H. R. \& Leslie, A. G. (2011). iMOSFLM: a new graphical interface for diffraction-image processing with MOSFLM. Acta Crystallogr D Biol Crystallogr 67, 271-81.

45. Otwinowski, Z. \& Minor, W. (1997). Processing of X-ray diffraction data collected in oscillation mode. Methods Enzymol 276, 307-26.

46. DeLano, W. L. (2010). The PyMOL Molecular Graphics System, 1.3 ed. Schro€dinger, LLC.

47. Cheng, P. N. \& Nowick, J. S. (2011). Giant macrolactams based on beta-sheet peptides. J Org Chem 76, 3166-73.

48. Spencer, R. K., Li, H. \& Nowick, J. S. (2014). X-ray crystallographic structures of trimers and higher-order oligomeric assemblies of a peptide derived from Abeta(17-36). J Am Chem Soc 136, 5595-8.

49. Bergfors, T. (2003). Seeds to crystals. J Struct Biol 142, 66-76.

50. Schindelin, J., Arganda-Carreras, I., Frise, E., Kaynig, V., Longair, M., Pietzsch, T., Preibisch, S., Rueden, C., Saalfeld, S., Schmid, B., Tinevez, J. Y., White, D. J., Hartenstein, V., Eliceiri, K., Tomancak, P. \& Cardona, A. (2012). Fiji: an open-source platform for biological-image analysis. Nat Methods 9, 676-82.

\section{Figure legends}

Figure 1. Structure of the $\mathrm{CdiA}-\mathrm{CT} / \mathrm{Cdil}{ }_{011}{ }^{\mathrm{EC} 869}$ complex and alignments of toxin and immunity homologs. (A) Cartoon representation of the CdiA-CT/Cdil ${ }_{011}{ }^{\mathrm{EC} 869}$ complex structure (PDB ID: 4G6U) with the toxin and immunity colored green and cyan, respectively. Toxin active-site residues are rendered in space-filling model and the $\mathrm{Zn}^{2+}$ ion is represented by a purple sphere. (B) Protein sequence alignment of the $\mathrm{CdiA}-\mathrm{CT}_{011}{ }^{\mathrm{EC} 869}$ nuclease domain and its homologues. Active-site residues are outlined in red boxes, and the $\beta 4 / \beta 5$-hairpin is outlined in a green box. (C) Protein sequence alignment of the $\mathrm{Cdil}_{011}{ }^{\mathrm{EC} 869}$ immunity protein and its homologues. Residues that form H-bond or ionpair interactions with $\mathrm{CdiA}-\mathrm{CT}_{011}{ }^{\mathrm{EC} 869}$ are marked with green boxes. The location of $\mathrm{Cdil}^{\mathrm{YPIII}}$ elongated loop $\left(E-L^{*}\right)$ is indicated with a magenta bar. For panels B \& C, alignments were prepared using Jalview, 
with progressively darker shades of purple indicating greater residue conservation. The secondary structure elements shown are from the CdiA-CT/Cdil ${ }_{011}{ }^{\mathrm{EC} 869}$ complex structure.

Figure 2. The structure of the CdiA-CT/Cdil ${ }^{\text {YPIII }}$ complex. (A) Ribbon representation of the CdiACT/Cdil ${ }^{\text {YIIII }}$ complex with toxin and immunity proteins colored in orange and purple, respectively. Location of the CdiA-CT $T^{\mathrm{YPIII}} \beta 4 / \beta 5$-hairpin is indicated. (B) Structural superimposition of the $\beta$-hairpin

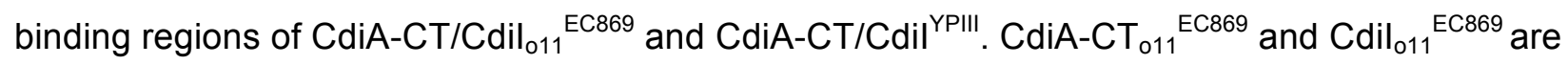
colored green and cyan, respectively. CdiA-CT ${ }^{\mathrm{YPIII}}$ residues that form a salt-bridge via loop $\mathrm{L} 1$ are depicted as sticks. (C) Predicted active site residues of $\mathrm{CdiA}_{-} \mathrm{CT}_{011}{ }^{\mathrm{EC} 869}$ (carbons in green) and CdiA$\mathrm{CT}^{\mathrm{YPIII}}$ (carbons in orange). Residue labels correspond to both toxins. The $\mathrm{Zn}^{2+}$ ion was observed in the CdiA-CT ${ }_{011}{ }^{E C 869}$ structure and is shown as a purple sphere. Extended loop (E-L*) of Cdil ${ }^{\text {YPIII }}$ is labeled in panels $\mathbf{A}$ and $\mathbf{B}$.

Figure 3. Comparison of the $\beta$-augmentation interactions. (A) Ribbon representation of the CdiA$\mathrm{CT} / \mathrm{Cdil}_{011}{ }^{\mathrm{EC} 869}$ complex with toxin and immunity proteins are colored green and cyan, respectively. Residues at the complex interface involved in direct ion pair or $\mathrm{H}$-bond interactions are shown in stick representation, with carbon atoms are colored as stated for above, oxygen and nitrogen atoms are colored red and blue, respectively. Water molecules at the interface are represented as red spheres. (B) Ribbon representation of the CdiA-CT/Cdil ${ }^{\text {YPIII }}$ complex with toxin and immunity proteins colored in orange and purple, respectively. Residues and water molecules represented and colored as in panel A.

Figure 4. CdiA-CT ${ }^{\text {YPIII }}$ has DNase activity in vitro. Supercoiled plasmid DNA was incubated with purified CdiA-CT ${ }_{011}{ }^{\mathrm{EC} 869}$ or CdiA-CT ${ }^{\mathrm{YPIII}}$ in the presence of either $\mathrm{Mg}^{2+}$ or $\mathrm{Zn}^{2+}$ and then analyzed by agarose gel electrophoresis and ethidium bromide staining. Reactions were supplemented with purified $\mathrm{Cdil}_{011}{ }^{\mathrm{EC} 869}$ or Cdil ${ }^{\mathrm{YPIII}}$ immunity proteins where indicated. Untreated supercoiled plasmid substrate and linearized plasmid were included as controls for the migration of undigested DNA. The migration positions of linear molecular weight (MW) DNA standards are indicated in kilobase pairs (kbp). 
Figure 5. Cdil $_{011}{ }^{\mathrm{EC} 869}$ and Cdil ${ }^{\mathrm{YPIII}}$ confer specific immunity to CDI. (A) Competition co-cultures. Inhibitors cells that deploy CdiA-CT ${ }_{011}{ }^{\mathrm{EC} 869}$ (from pCH9305) or $\mathrm{CdiA}^{-\mathrm{CT}^{\mathrm{YPIII}}}$ (from pCH2409) were incubated at a 1:1 ratio with target cells that express $\mathrm{Cdil}_{011}{ }^{\mathrm{EC} 869}$ (from pCH9315), Cdil ${ }^{\mathrm{YPIII}}$ (from pCH848) or no immunity at all (none, pTrc99a vector). Viable target cells were quantified as colonyforming units (cfu) per milliliter at the beginning of the co-culture and after $4 \mathrm{~h}$. Data represent the average \pm standard error of the mean for three independent experiments. (B) Fluorescence microscopy of competition co-cultures. YFP-labeled inhibitor cells were co-cultured with mKate2-labeled target strains that carry the indicated immunity genes. Cells were stained with DAPI to visualize genomic DNA at zero and four hours of co-culture.

Figure 6. Deletion of the CdiA-CT ${ }_{011}{ }^{\mathrm{EC} 869} \beta$-hairpin disrupts complex formation. (A) Ribbon representation of the CdiA-CT/Cdil ${ }_{011}{ }^{\mathrm{EC} 869}$ complex interface. CdiA-CT ${ }_{011}{ }^{\mathrm{EC} 869}, \mathrm{Cdil}_{011}{ }^{\mathrm{EC} 869}$ and the $\beta$ hairpin colored in green, cyan, and olive, respectively. The Gly-Ser-Gly linker in CdiA-CT ${ }_{011}{ }^{E C 869 / \triangle \beta 4 \beta 5}$ is depicted as a dashed red line. (B) $\mathrm{His}_{6}$-tagged $\mathrm{Cdil}_{011}{ }^{\mathrm{EC} 869}$ was co-expressed with $\mathrm{CdiA}-\mathrm{CT}_{011}{ }^{\mathrm{EC} 869}$ or $\mathrm{CdiA}-\mathrm{CT}_{011}{ }^{\mathrm{EC} 869 / \Delta \beta 4 \beta 5}$, followed by purification via $\mathrm{Ni}^{2+}$-affinity chromatography and then analysis by SDS/PAGE gel. Relevant molecular weight standards are labeled. The flow-through (FT), wash (W) and elution fractions (E) are indicated. (C) Circular dichroism spectra of purified CdiA-CT ${ }_{011}{ }^{\text {EC869 }}$ and CdiA-CT ${ }_{011}^{E C 869 / \triangle \beta 4 \beta 5}$.

Figure 7. Toxin $\beta$-hairpin sequence contributes to complex binding affinity. (A) Protein sequence alignment of the $\beta$-hairpin region (boxed) of $\mathrm{CdiA}^{-} \mathrm{CT}_{011}{ }^{\mathrm{EC} 869}, \mathrm{CdiA}^{-} \mathrm{CT}^{\text {Nlact }}$ and $\mathrm{CdiA}-\mathrm{CT}^{\mathrm{Ykris}}$. CdiA$\mathrm{CT}_{011}{ }^{\mathrm{EC} 869}$ residues that interact with $\mathrm{Cdil}_{011}{ }^{\mathrm{EC} 869}$ are shown in green. Red residues indicate sequence differences with respect to $\mathrm{CdiA}_{-} \mathrm{CT}_{011}{ }^{\mathrm{EC} 869}$. (B) $\mathrm{Cdil}_{\mathrm{o} 11}{ }^{\mathrm{EC} 869}-\mathrm{His}_{6}$ was co-expressed with $\mathrm{CdiA}-\mathrm{CT}_{011}{ }^{\mathrm{EC} 869}$ containing the $\beta$-hairpins from either $N$. lactamica or $Y$. kristensenii. Then purified by $\mathrm{Ni}^{2+}$-affinity chromatography and analyzed by SDS-PAGE. The molecular weight standards are indicated in kDa. The flow-though (FT) and wash fractions (W1 and W2) are indicated followed by elution with imidazole 
gradient. (C) Circular dichroism spectra of purified CdiA-CT ${ }_{011}{ }^{E C 869 / N l a c t}$ and $C \operatorname{diA}-C_{011}{ }^{E C 869 / Y k r i s ~}$ show similar secondary structure content compared to wild-type CdiA-CT ${ }_{011}{ }^{\mathrm{EC} 869}$.

Figure 8. Structure of the MAC-Cdil ${ }_{011}{ }^{\mathrm{EC} 869}$ complex. (A) Crystal structure with $\mathrm{Cdil}_{\mathrm{O} 11}{ }^{\mathrm{EC} 869}$ depicted as orange ribbons, and MAC displayed as sticks, carbon, nitrogen, oxygen, and ornithine carbons colored mageneta, blue, red, and pink, respectively. The MAC $2 F_{0}-F_{c}$ electron density map is shown in grey mesh and contoured at $1.0 \sigma$. (B) Structural superimposition of MAC (colored same as panel A) and the CdiA-CT/Cdil ${ }_{011}{ }^{\text {EC869 }}$ complex. Only residues Lys242 - Ser253 of the CdiA-CT $011{ }^{E C 869} \beta$-hairpin are shown (green). Cdil $_{011}{ }^{\mathrm{EC} 869}$ is colored teal and helix $\alpha 3^{*}$ is labeled. C) MAC interacts with Cdil ${ }_{011}{ }^{\mathrm{EC} 869}$ through a network of $\mathrm{H}$-bonds and ion pairs. Interacting bonds are shown as black dotted lines.

Cdil $_{011}{ }^{\mathrm{EC} 869} \beta$-strands that $\mathrm{H}$-bond with MAC $\left(\beta 3^{*}\right.$ and $\left.\beta 7^{*}\right)$ are shown as sticks. D) Surface representation of the $\mathrm{Cdil}^{\mathrm{CT}-\mathrm{MAC}}$ structure, oriented as in panels $\mathrm{A}$ and $\mathrm{B}$, depicting the complementarity of MAC and Cdil $_{011}$ EC869. 
Table 1. X-ray diffraction data and atomic refinement

\begin{tabular}{|c|c|c|c|}
\hline & CdiA-CT/Cdil YPIII & Cdil Ykris & $\mathrm{MAC} / \mathrm{Cdil}_{\mathrm{o} 11} \mathrm{EC}^{\mathrm{E} 69}$ \\
\hline Space Group & $\mathrm{C} 2$ & $\mathrm{P} 3_{1}$ & $\mathrm{P} 2_{1}$ \\
\hline \multicolumn{4}{|l|}{ Unit cell dimensions } \\
\hline$a, b, c(\AA)$ & $65.5,65.5,71.5$ & $54.4,54.4,54.4$ & $34.8,128.2,45.0$ \\
\hline$\beta\left(^{\circ}\right)$ & 92.18 & & 112.73 \\
\hline $\mathrm{pH}$ of crystallization condition & 7.0 & 7.4 & 6.0 \\
\hline Protein concentration $(\mathrm{mg} / \mathrm{mL})$ & 10 & 12.5 & 7.5 \\
\hline \multicolumn{4}{|l|}{ Data set } \\
\hline Wavelength $(\AA)$ & 1.0 & 1.0 & 1.0 \\
\hline Resolution range & $46.49-2.1$ & $50.0-1.8$ & $50.0-2.0$ \\
\hline Unique reflections (total) & 18152 & 16618 & 23561 \\
\hline Completeness (\%) ${ }^{*}$ & $99.4(98.3)$ & $99.7(100)$ & $96.5(92.1)$ \\
\hline Redundancy * & $3.5(3.5)$ & $5.4(5.5)$ & $3.1(3.1)$ \\
\hline$R_{\text {merge }}{ }^{* \dagger}$ & $0.059(0.460)$ & $0.161(0.607)$ & $0.076(0.485)$ \\
\hline $1 / \sigma(I)^{*}$ & $10.0(1.6)$ & $9.48(3.1)$ & $11.1(3.1)$ \\
\hline NCS copies & 1 & 1 & 2 \\
\hline Other ions & $2 \mathrm{Cl}^{-}$ & - & $2 \mathrm{Cl}^{-}$ \\
\hline \multicolumn{4}{|l|}{ Model refinement } \\
\hline Resolution range $(\AA)$ & $46.49-2.09$ & $23.58-1.80$ & $34.81-2.00$ \\
\hline No. of reflections & $18149 / 1851$ & $16580(1673)$ & $23526(2004)$ \\
\hline No. of protein atoms & 2308 & 1283 & 2596 \\
\hline No. of water molecules & 148 & 130 & 132 \\
\hline No. of CT-MAC atoms & - & - & 222 \\
\hline Missing residues & $\begin{array}{c}1-173,298(\mathrm{CdiA}) \\
1-2,(\mathrm{Cdil})\end{array}$ & none & $1,168,169$ \\
\hline$R_{\text {work }} / R_{\text {free }}{ }^{\ddagger}, \%$ & $20.5 / 25.6$ & $18.1 / 22.1$ & $18.4 / 23.1$ \\
\hline \multicolumn{4}{|l|}{ R.m.s deviations } \\
\hline Bond lengths $(\AA)$ & 0.003 & 0.007 & 0.009 \\
\hline Bond angles (degrees) & 0.694 & 0.998 & 1.222 \\
\hline \multicolumn{4}{|l|}{ Ramachandran Plot } \\
\hline Most favorable region (\%) & 95.25 & 98.77 & 97.13 \\
\hline Additional allowed region (\%) & 4.75 & 1.23 & 2.87 \\
\hline Disallowed region & 0 & 0 & 0 \\
\hline PDB ID Code & $4 Z Q U$ & $4 Z Q V$ & $4 Z Q W$ \\
\hline
\end{tabular}

${ }^{*}$ Statistics for the highest resolution shell are given in (brackets)

${ }^{\dagger} R_{\text {merge }}=\Sigma||-<|>| / \Sigma<1>$

${ }^{\ddagger} R_{\text {work }}=\Sigma \mid F_{\text {obs }}-F_{\text {cald }} / \Sigma F_{\text {obs }}$

$R_{\text {free }}$ was computed identically except where all reflections belong to a test set of $10 \%$ randomly selected data. 
Table 2. Dissociation constants $(\mu \mathrm{M})$ of $\mathrm{CdiA}-\mathrm{CT}$ and Cdil interactions determined using biolayer interferometry.

\begin{tabular}{|c|c|c|c|}
\hline & CdiA-CT $_{\text {o11 }}{ }^{\text {EC869 }}$ & CdiA-CT $_{\text {o11 }}$ EC869/Ykris & CdiA-CT $_{\text {o11 }}$ EC869/Nlact \\
\hline Cdil $_{\text {o11 }}{ }^{\text {EC869 }}$ & $0.018 \pm 0.007$ & $46 \pm 36$ & $0.18 \pm 0.10$ \\
\hline Cdil $^{\text {Ykris }}$ & $5.0 \pm 0.4$ & $24 \pm 14$ & $5.8 \pm 3$ \\
\hline Cdil $^{\text {Nlact }}$ & $82 \pm 18$ & $3.2 \pm 2$ & $0.17 \pm 0.09$ \\
\hline
\end{tabular}




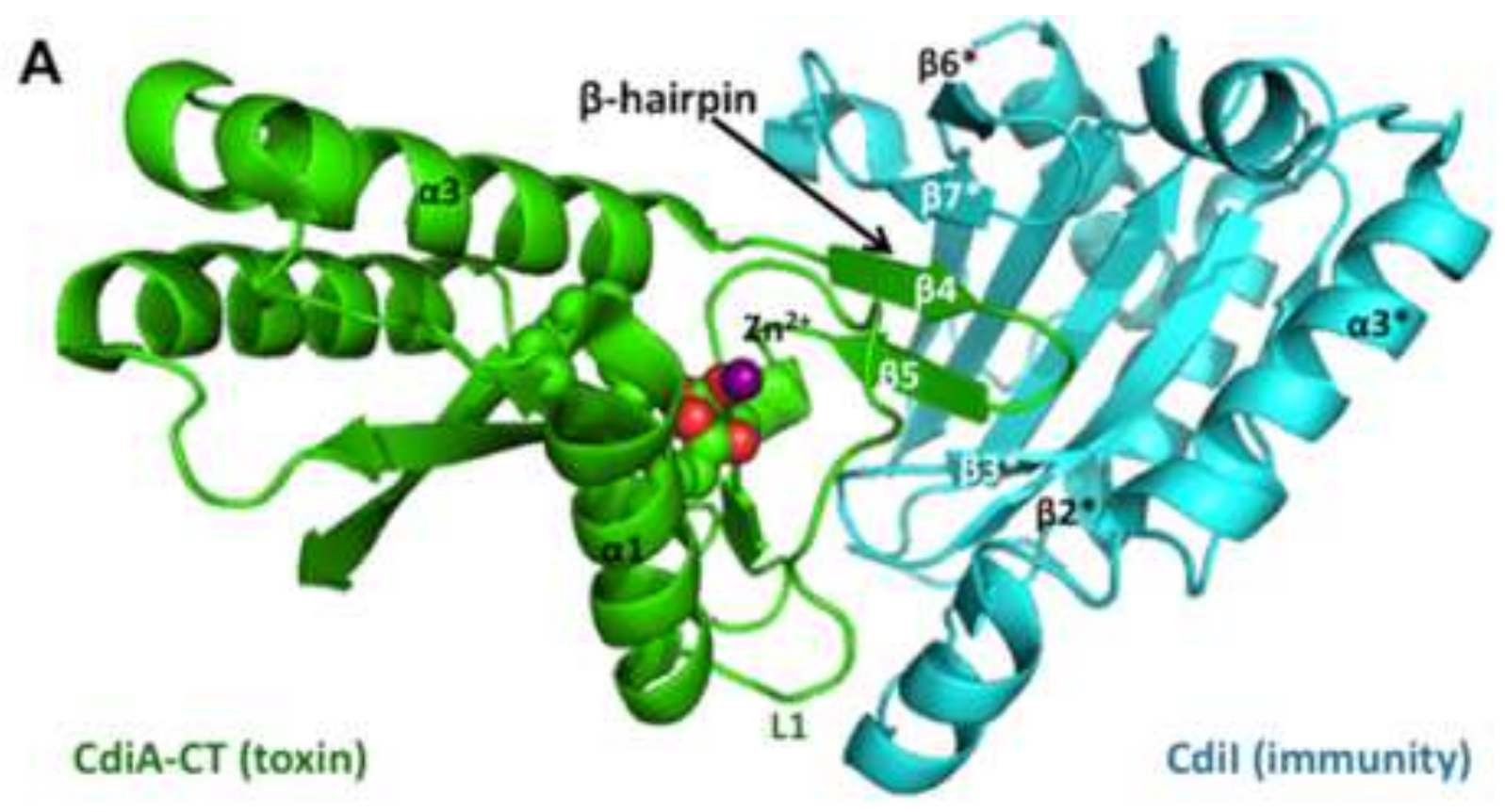

B

I entichs

Fintomen

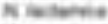

Cenomente

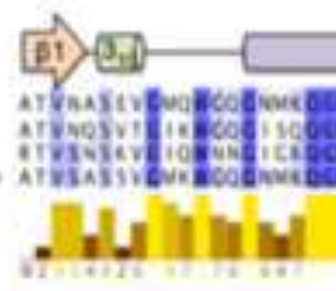

$\mathbf{L 1}$

21

$\sqrt[52]{102}$

13

a2

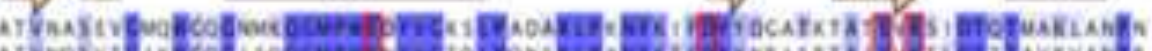

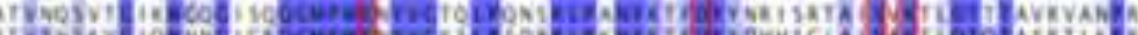

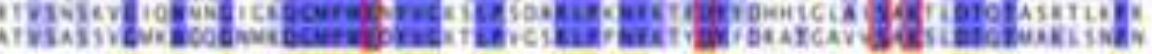

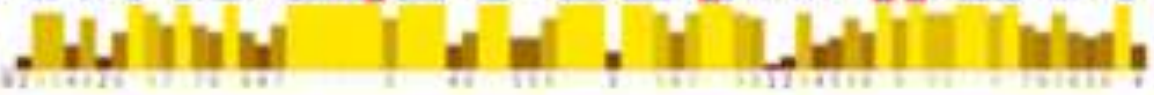

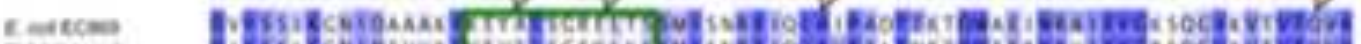

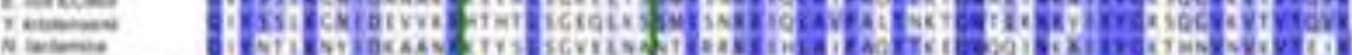

n

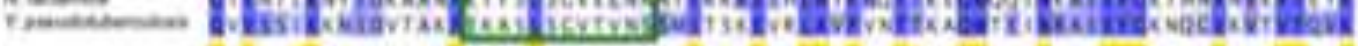

Cemente

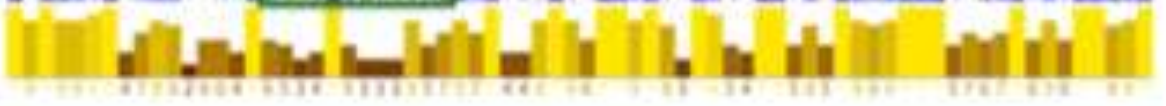

C
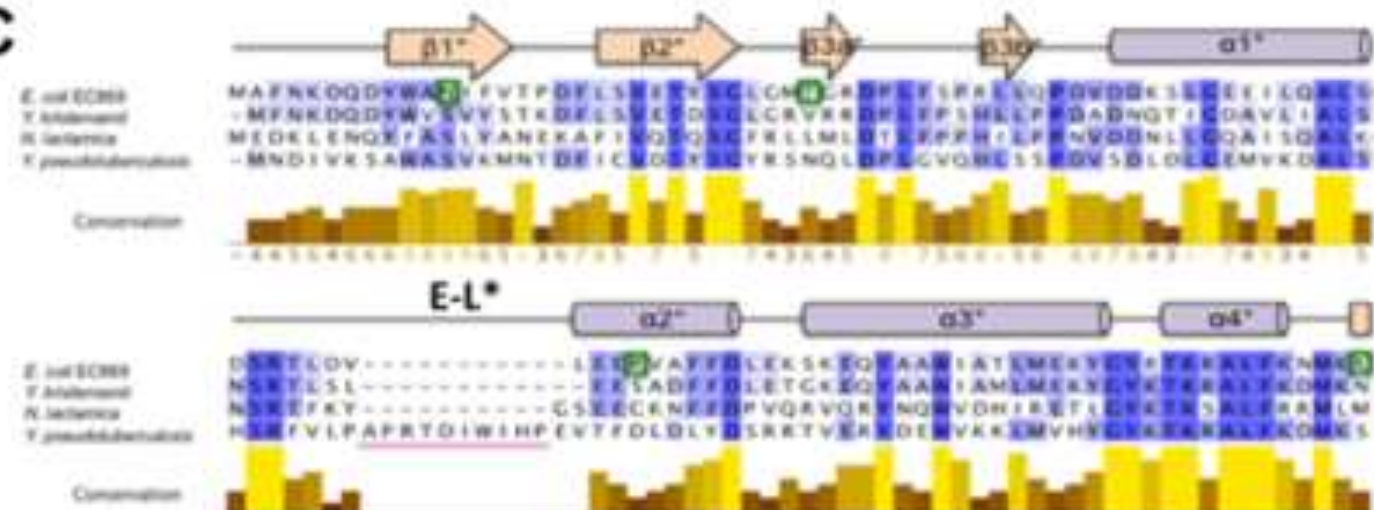

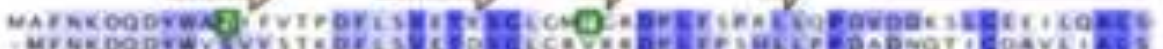

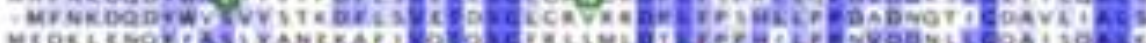

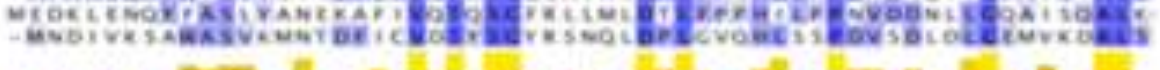

andion

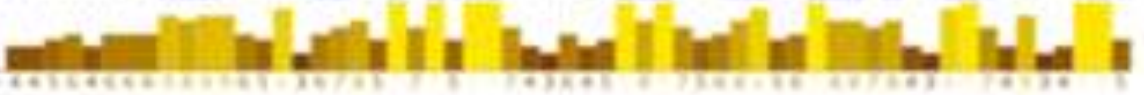
E-L*

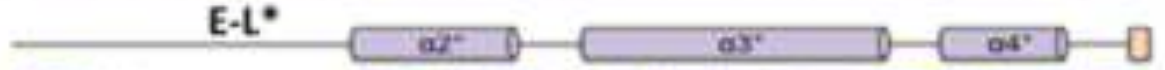

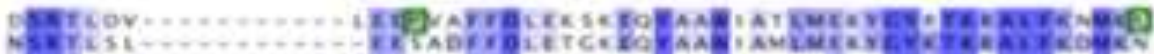

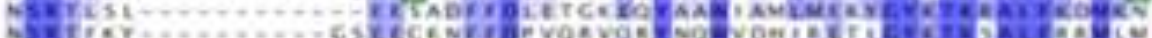

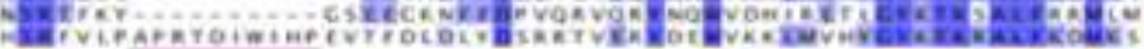

Conene

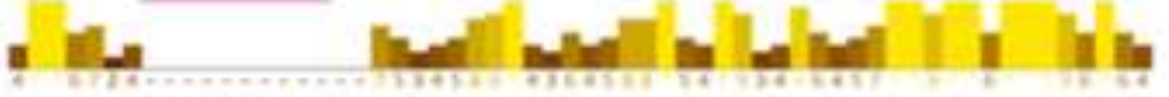

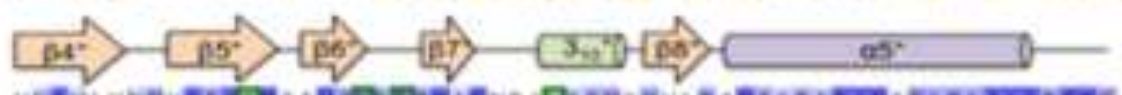

taren:

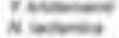

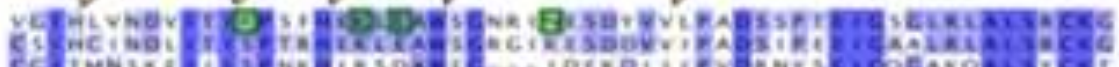

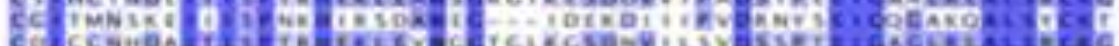

rementimats 

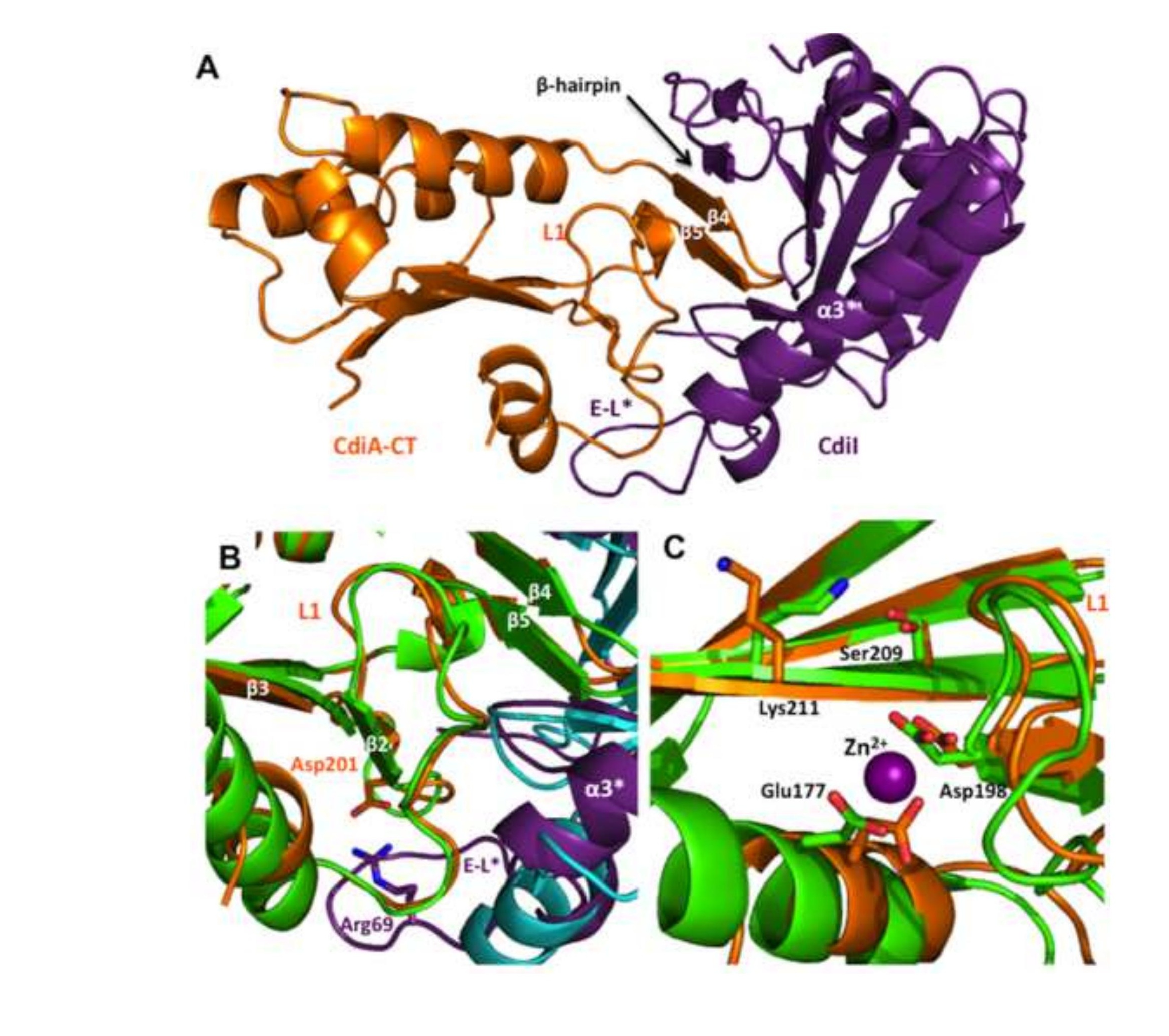

A

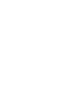

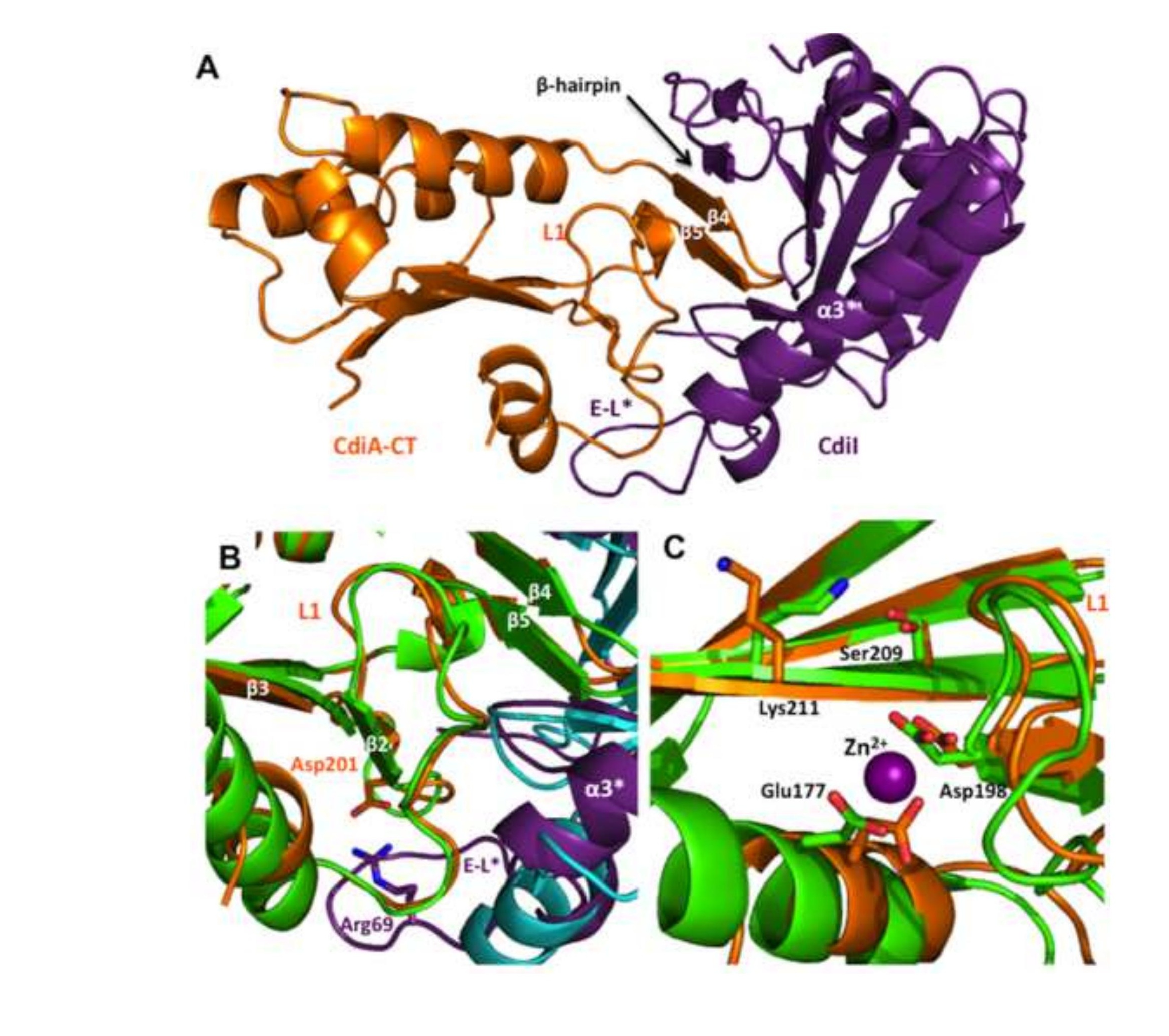

Fin

a
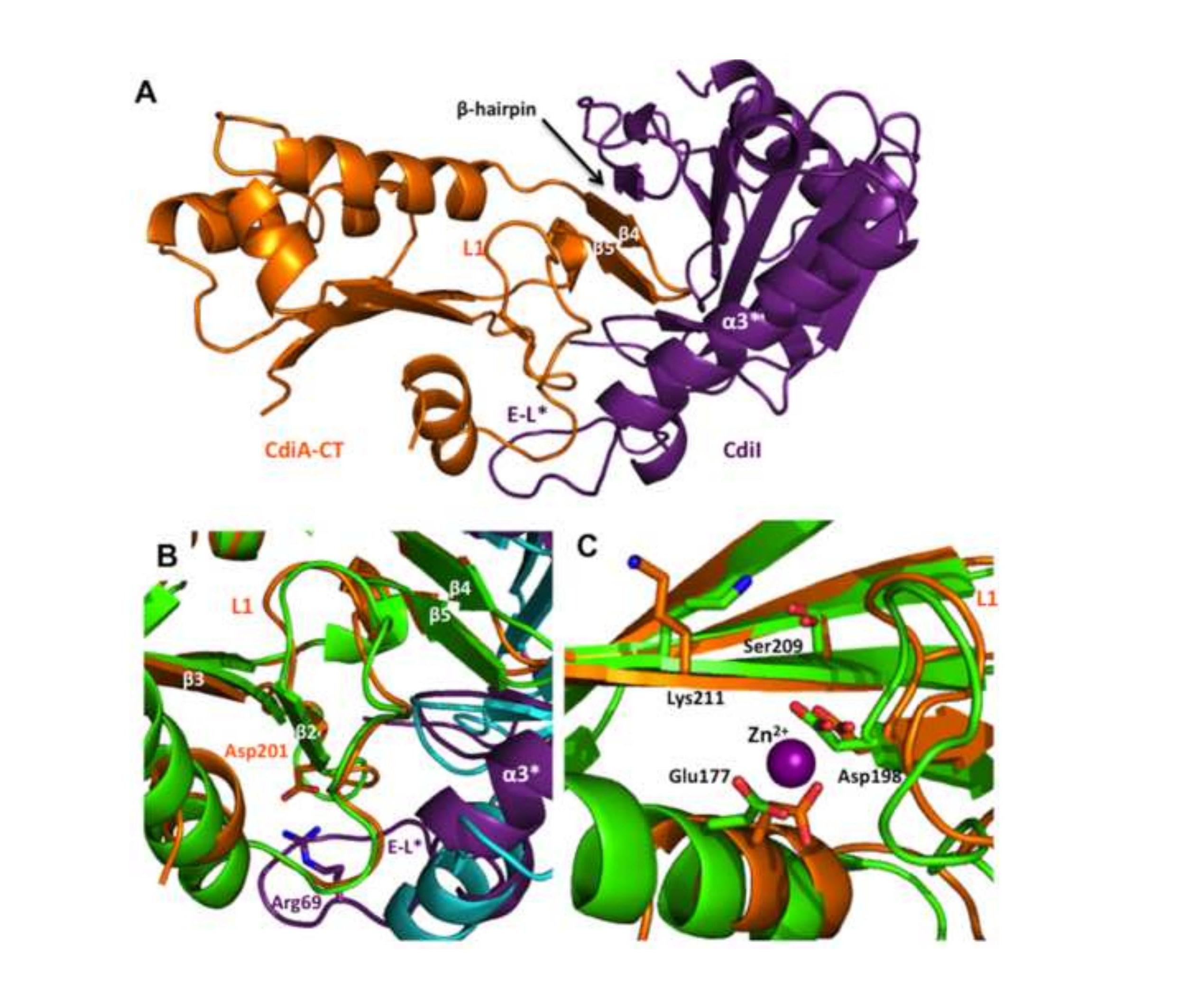

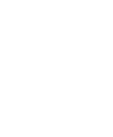
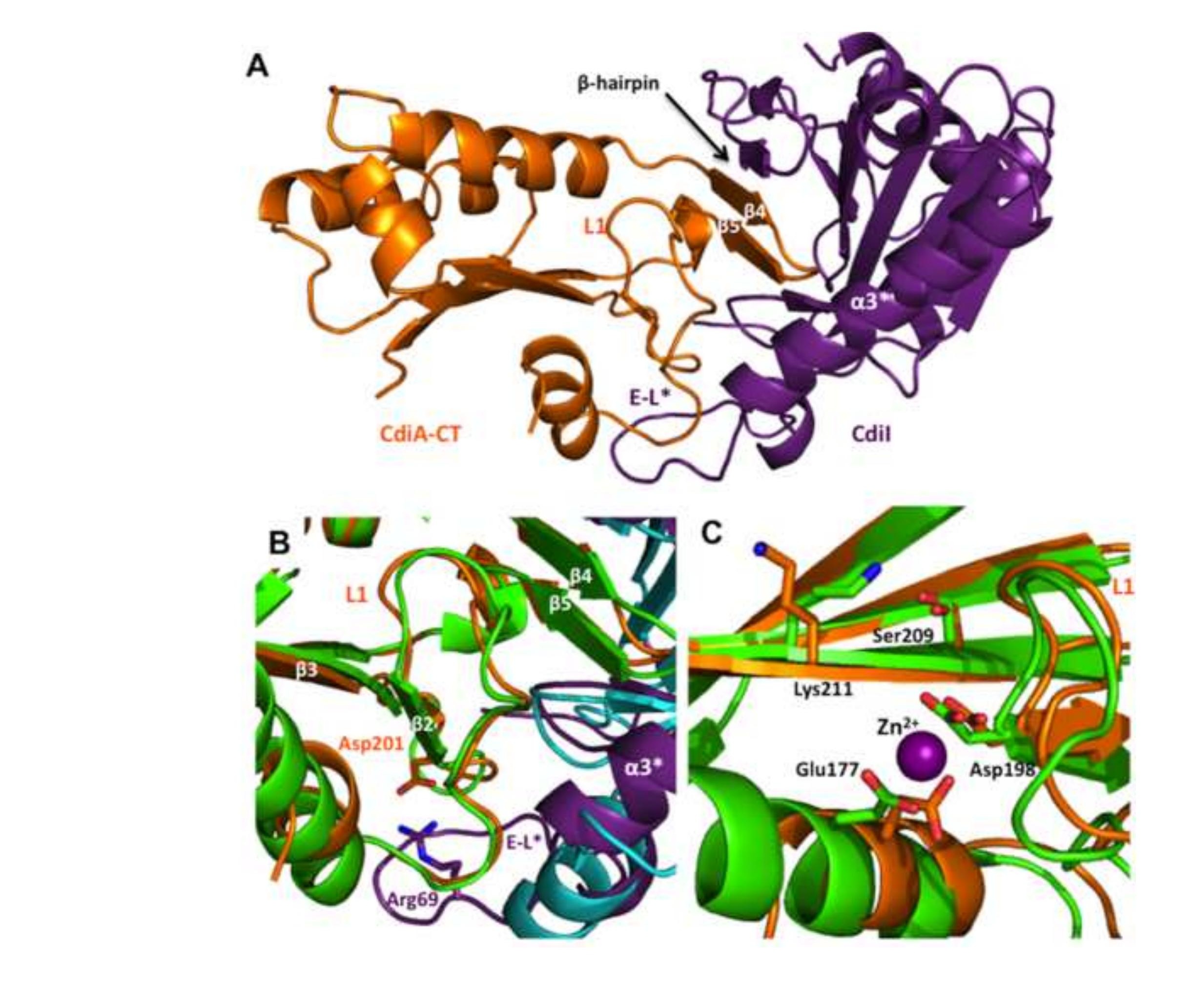

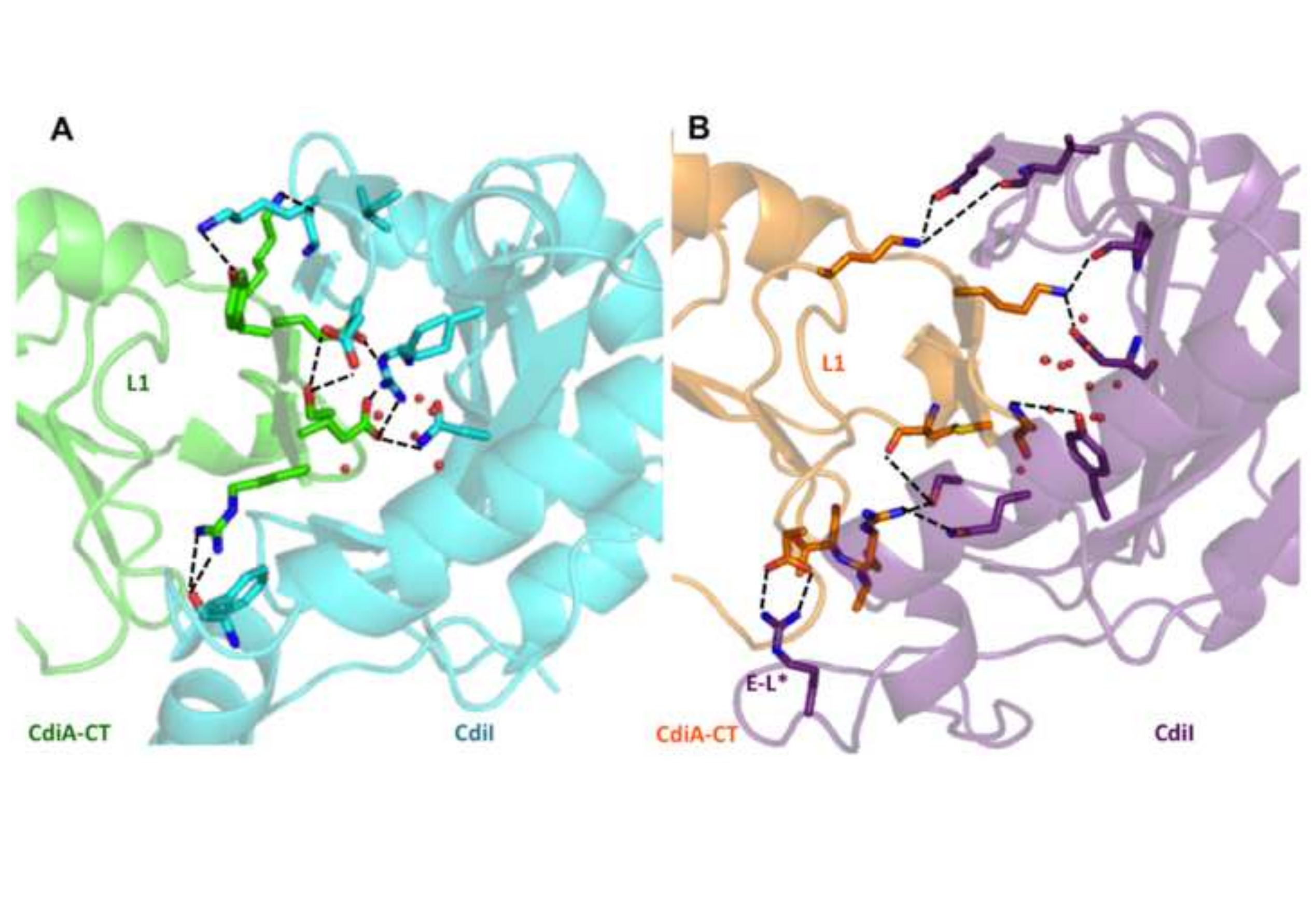

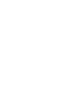

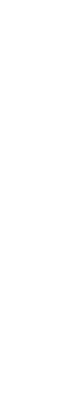

(

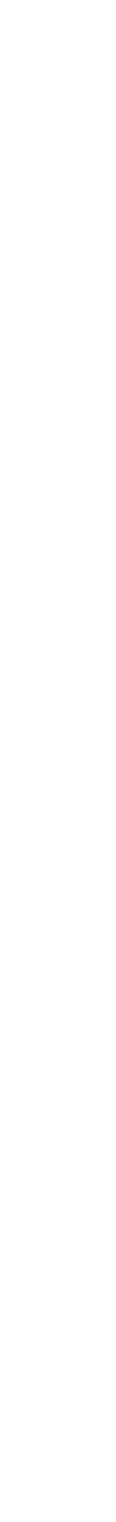

\author{
.
}

de

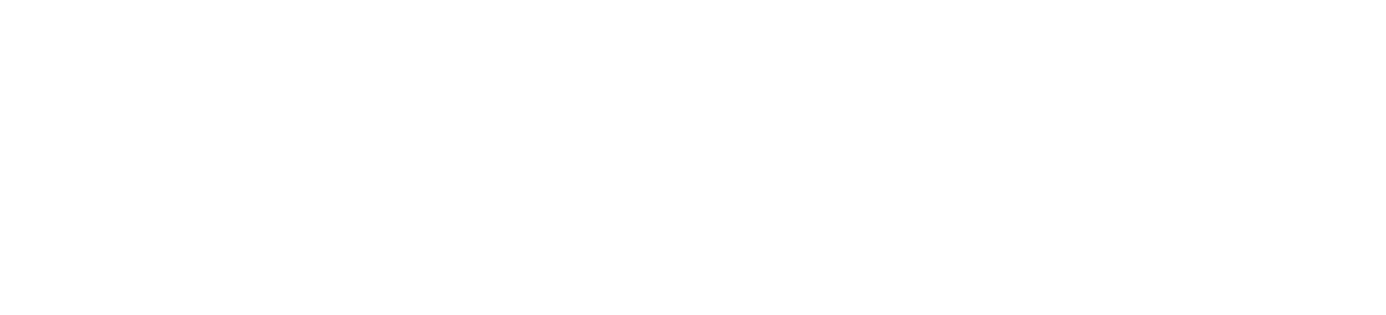



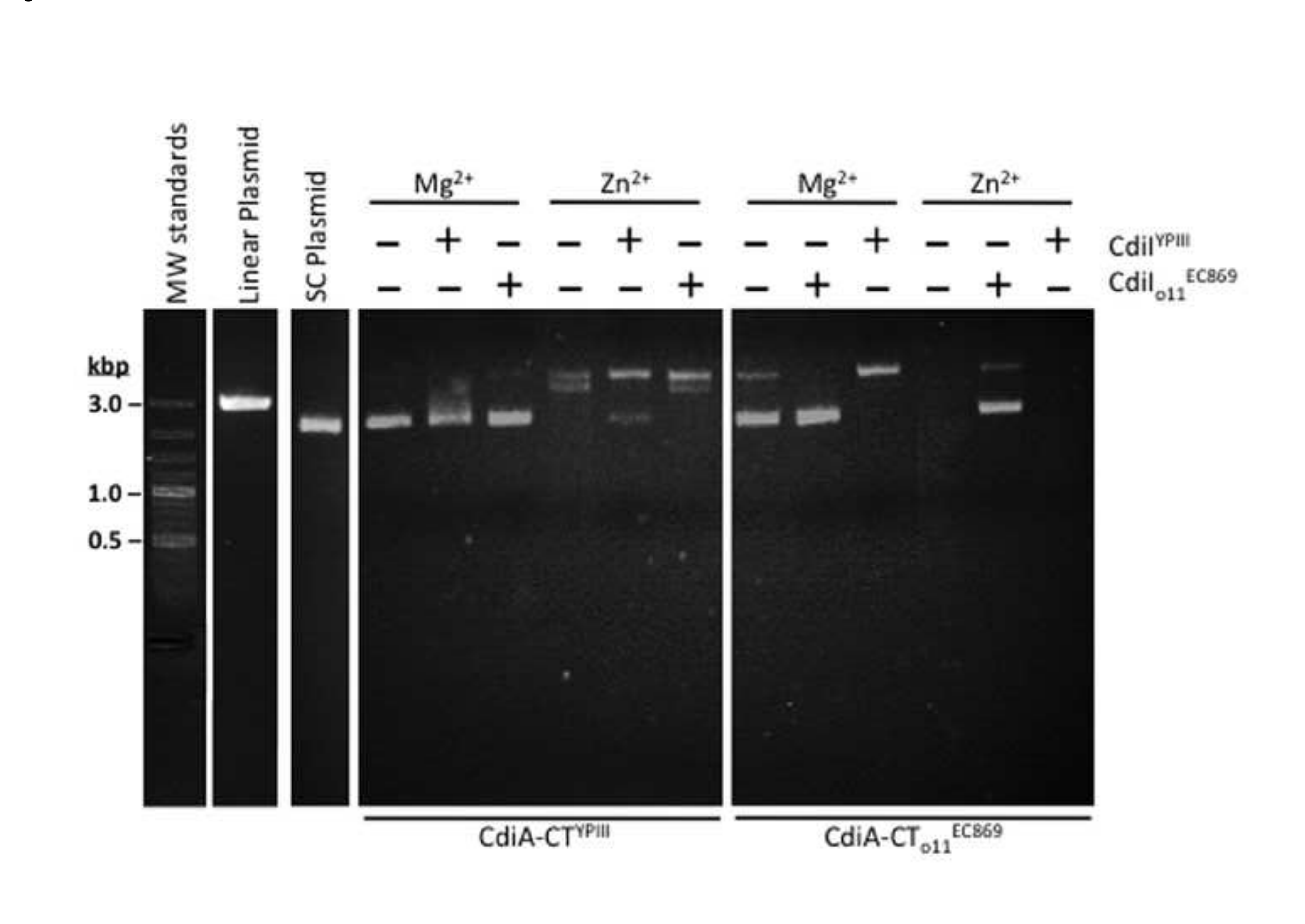
A
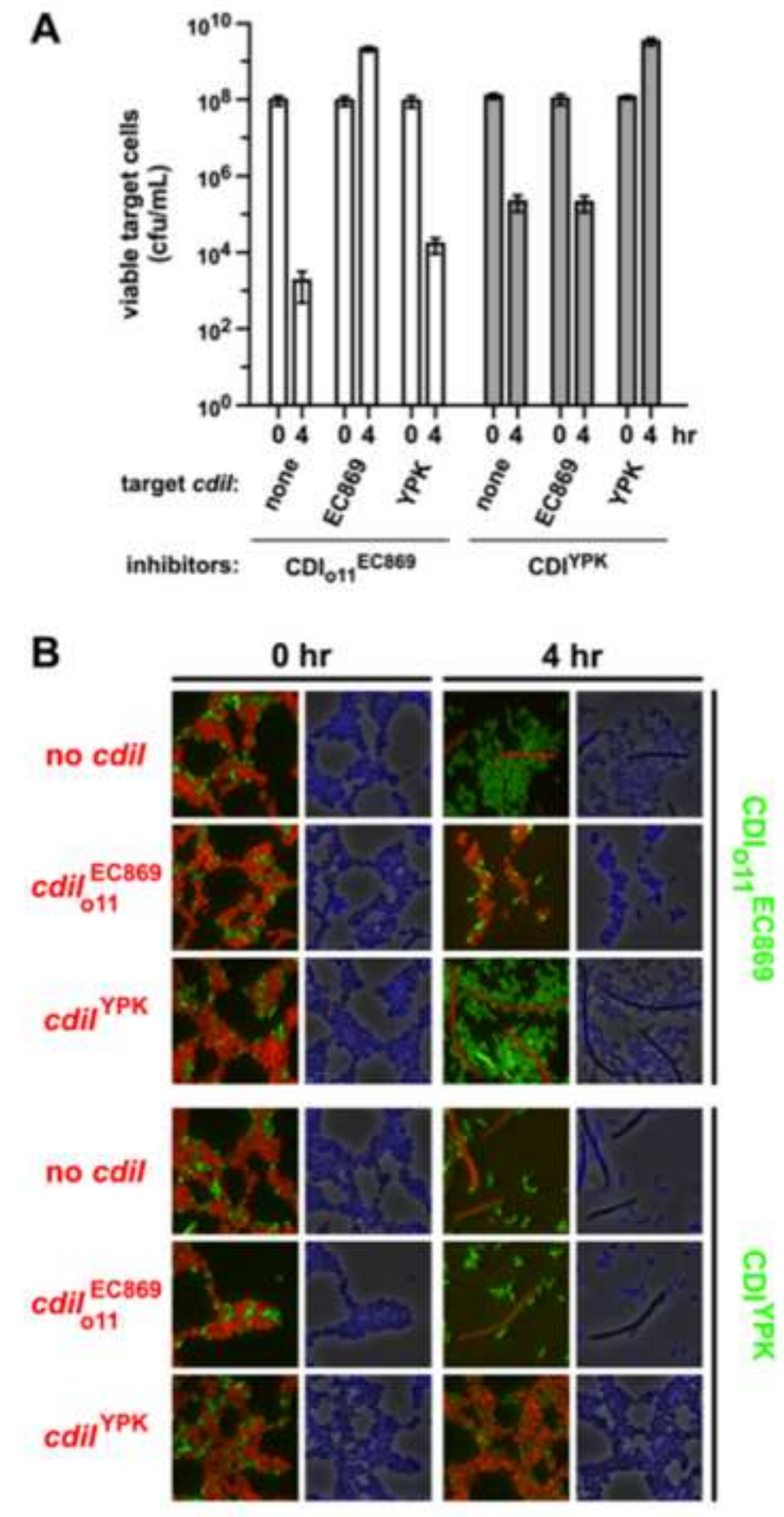

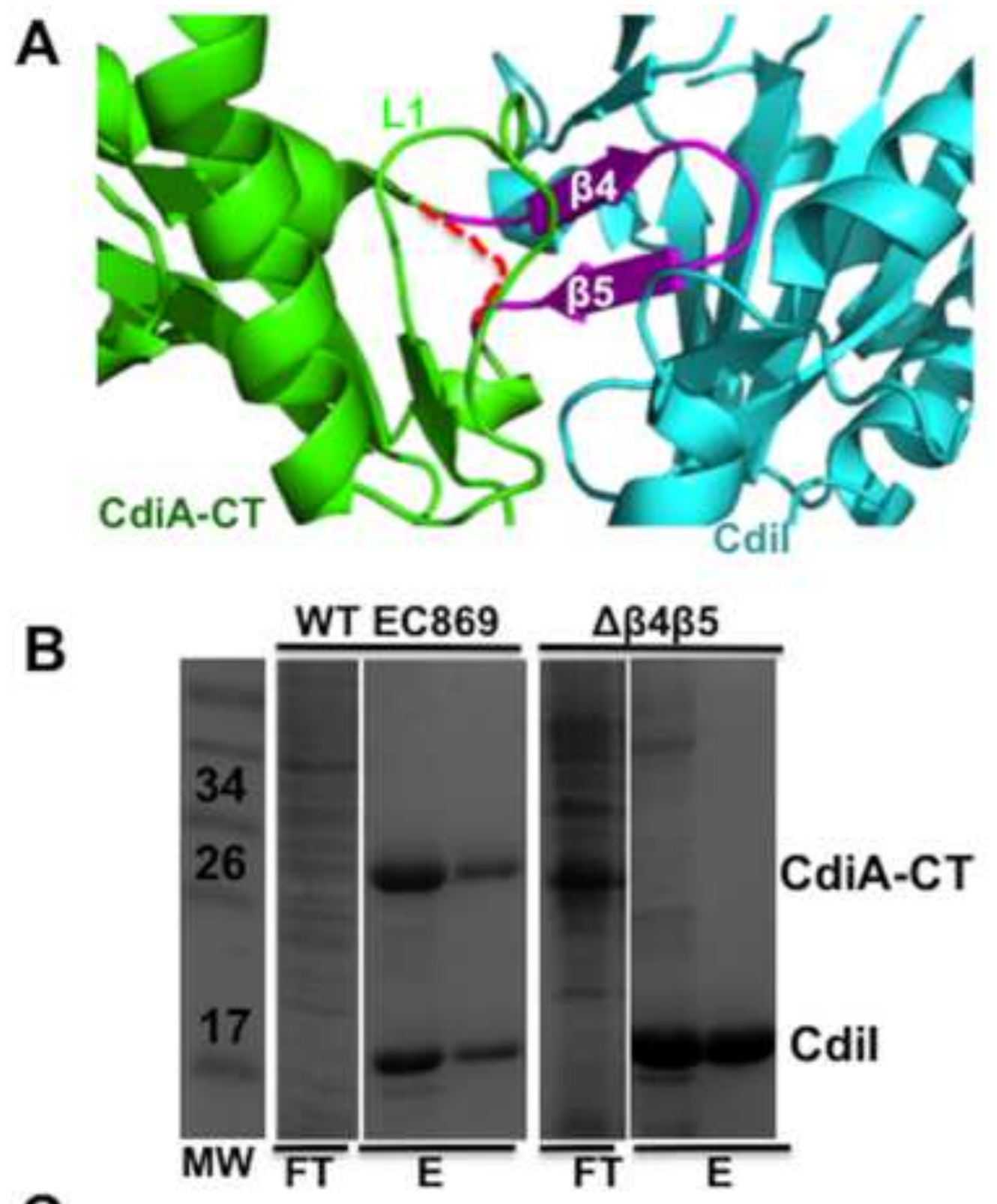

C

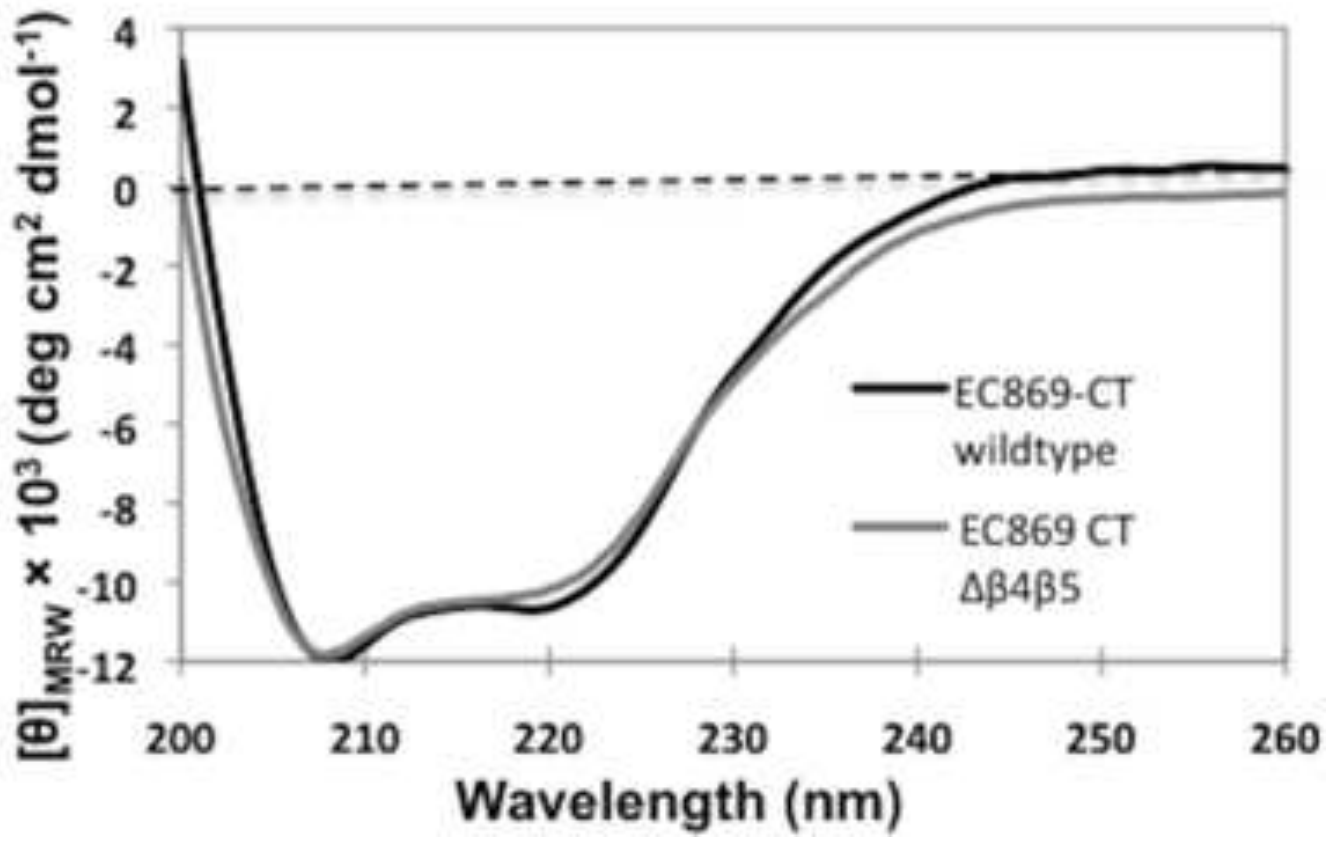


A

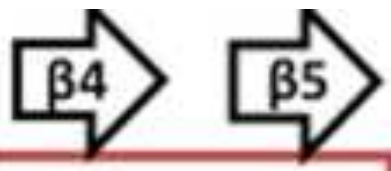

EC869 GNIDAAAKF KEYALSGRELTSSMISNREIQLAIP N. lactamica GNIDAAAKFKTYSLSGVELTS SMISNREIQLAIP Y. kristensenii GNIDAAAKEHTHTLSGEOLTS SMISNREIQLAIP

B

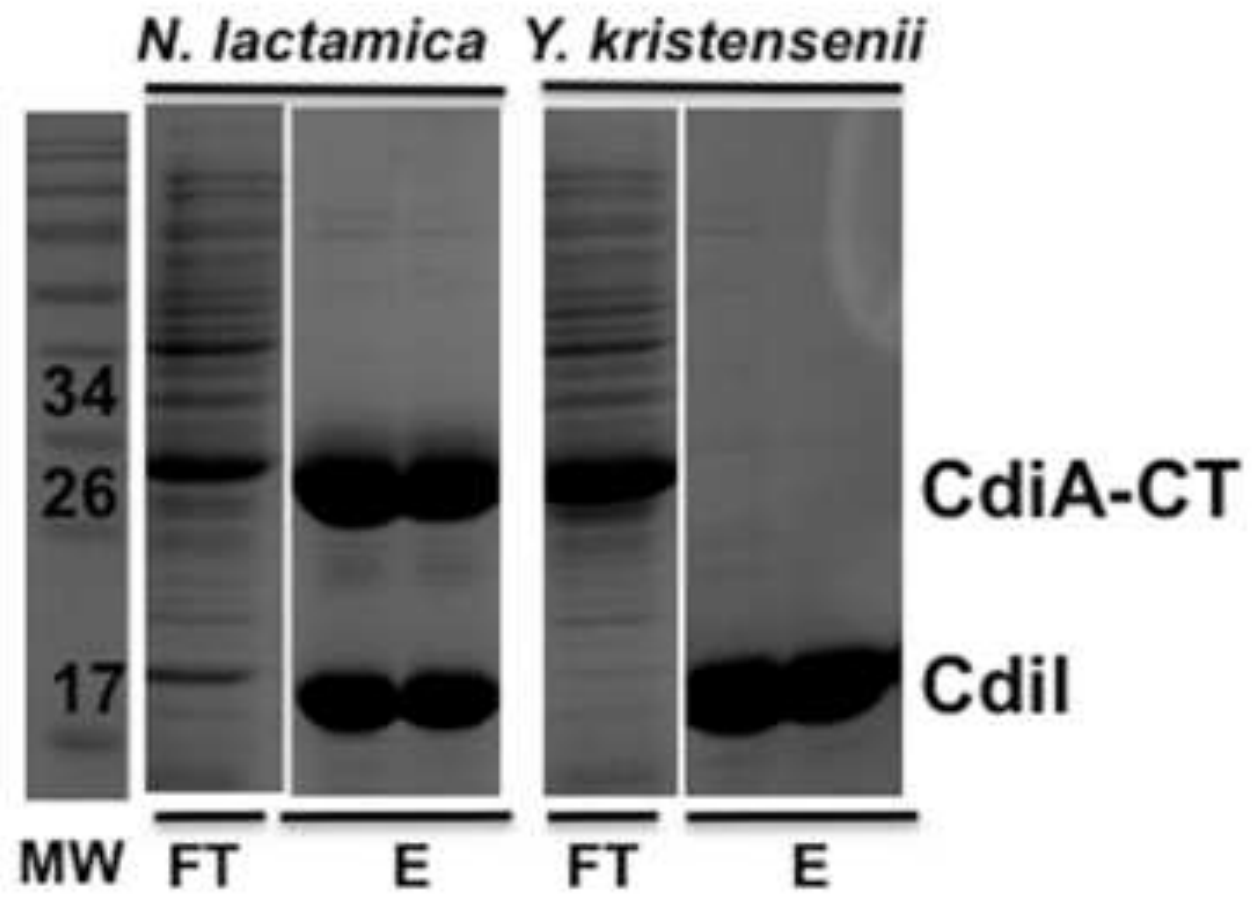

C

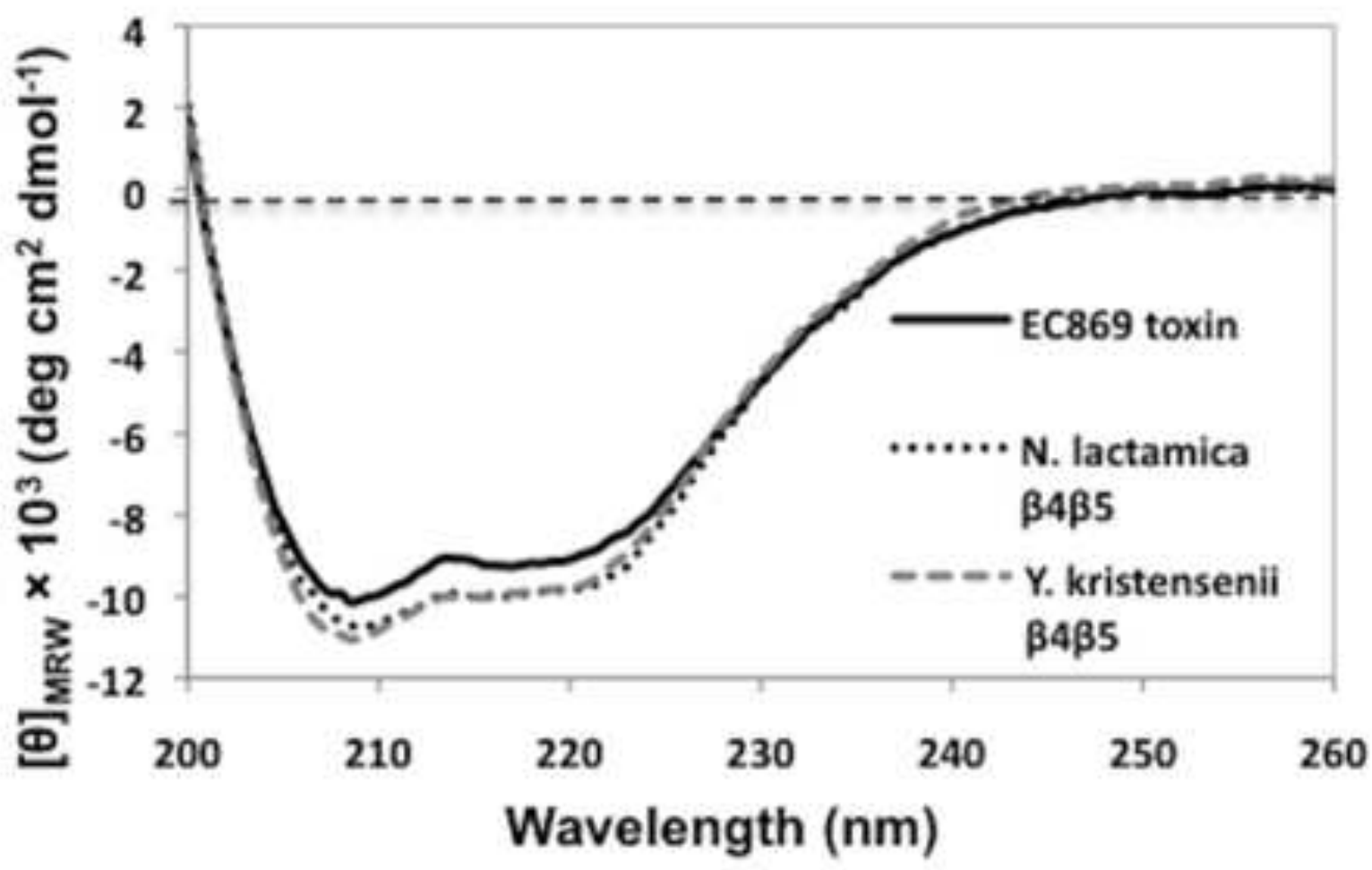



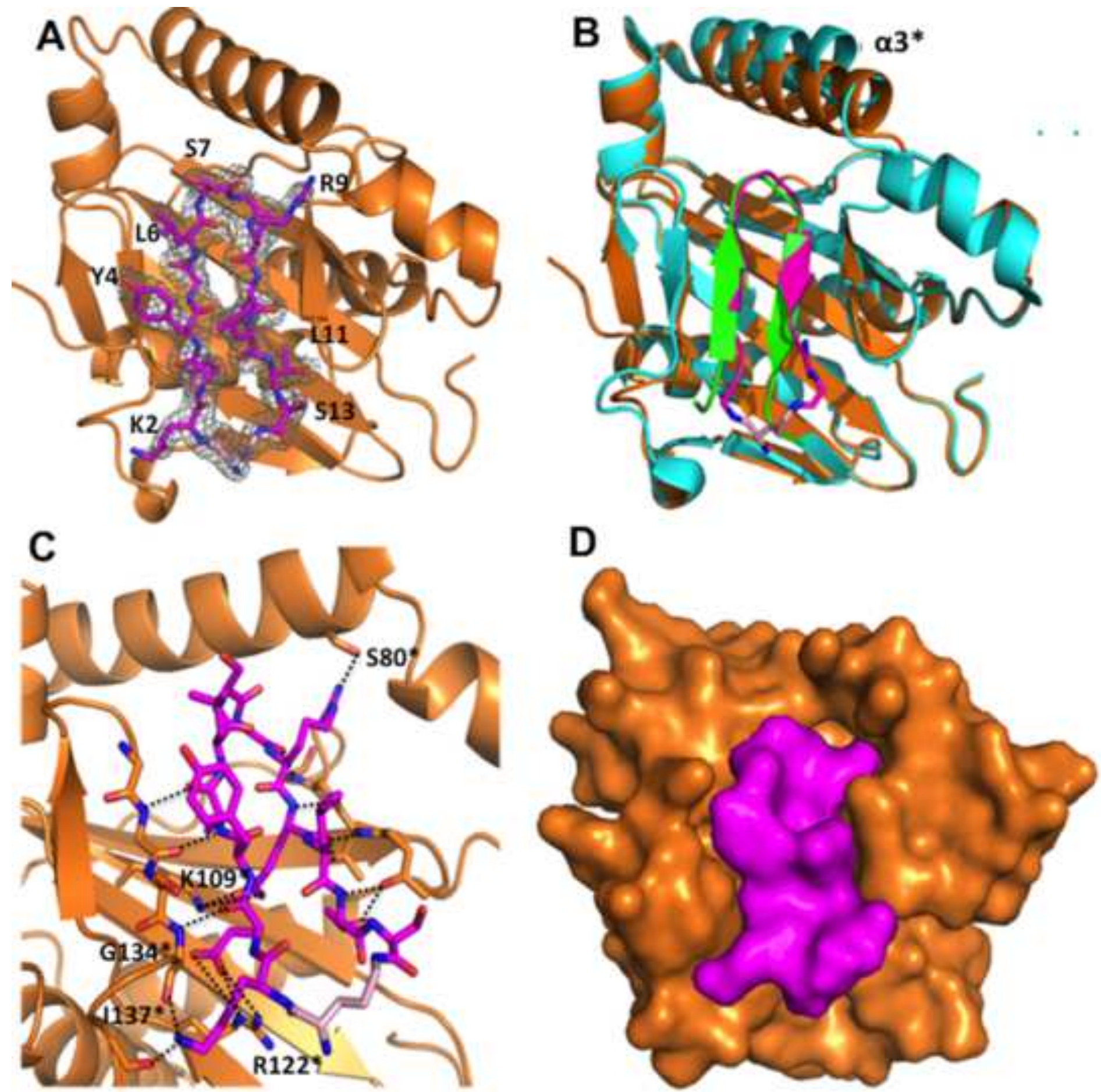